\title{
Viviendo con el diablo en casa. La enfermedad, hechicería infantil y violencia entre los asháninka desde la perspectiva misionera adventista
}

Vivre avec le diable. Maladie, sorcellerie infantile et violence chez les Ashaninka vues par les missionaires adventistes

Living with the devil in house. The disease, child sorcery and violence among the asháninka from the Adventist missionary perspective

Juan Carlos La Serna Salcedo

\section{OpenEdition}

Journals

Edición electrónica

URL: http://journals.openedition.org/bifea/1580

DOI: $10.4000 /$ bifea. 1580

ISSN: 2076-5827

Editor

Institut Français d'Études Andines

Edición impresa

Fecha de publicación: 1 abril 2011

Paginación: 81-121

ISSN: 0303-7495

Referencia electrónica

Juan Carlos La Serna Salcedo, «Viviendo con el diablo en casa. La enfermedad, hechicería infantil y violencia entre los asháninka desde la perspectiva misionera adventista », Bulletin de l'Institut français d'études andines [En línea], 40 (1) | 2011, Publicado el 01 octubre 2011, consultado el 06 noviembre 2020. URL : http://journals.openedition.org/bifea/1580 ; DOI : https://doi.org/10.4000/bifea.1580

\section{cc)}

Les contenus du Bulletin de l'Institut français d'études andines sont mis à disposition selon les termes de la licence Creative Commons Attribution - Pas d'Utilisation Commerciale - Pas de Modification 4.0 International. 


\title{
Viviendo con el diablo en casa. La enfermedad, hechicería infantil y violencia entre los asháninka desde la perspectiva misionera adventista
}

\author{
Juan Carlos La Serna Salcedo*
}

\begin{abstract}
Resumen
Desde su establecimiento en la selva central peruana, hacia la década de 1920, los misioneros adventistas han reportado constantemente la permanencia de una serie de manifestaciones rituales tradicionales entre los conversos asháninkas, las cuales, a pesar de la constante crítica y prédica misionera, siguen teniendo gran vitalidad hasta nuestros días. Entre estas, las que han sido mayormente denunciadas —y enfrentadas por la acción evangelizadora y pastoral— han sido las prácticas de shamanismo y las acusaciones de hechicería. En los últimos años este tema ha despertado un notorio interés dentro de la antropología amazónica; por eso el artículo propone una reflexión sobre las apreciaciones y juicios generados desde la perspectiva misionera acerca de estos fenómenos. A la vez anota cómo la cosmovisión de los indígenas conversos al adventismo, más allá de generar un rompimiento con su religiosidad tradicional y la aceptación de una explicación doctrinal cristiana sobre el origen del mal y la enfermedad, ha generado una interpretación compleja donde tienen vigencia concepciones tradicionales $\mathrm{y}$ «modernas» para entender el principio y la presencia del mal y el demonio en el mundo.
\end{abstract}

Palabras clave: selva central, asháninka, misiones, adventismo, brujería infantil, chamanismo

* Historiador y Magíster en Ciencias de la Religión de la Universidad Nacional Mayor de San Marcos (Lima). Primer puesto, premio François Bourricaud, 2008. E-mail: peruquechua@hotmail.com 


\title{
Vivre avec le diable. Maladie, sorcellerie infantile et violence chez les Ashaninka vues par les missionaires adventistes
}

\author{
Résumé
}

Depuis leur installation dans la Selva centrale péruvienne au cours des années 1920, les missionnaires adventistes ont systématiquement signalé la permanence d'une série de manifestations rituelles traditionnelles parmi les convertis ashaninkas qui continuent de jouir d'une grande vitalité malgré les constantes critiques et prédications des missionnaires. Parmi ces manifestations, qui furent généralement dénoncées — et combattues par l'action évangélisatrice et pastorale—, on trouve des pratiques chamaniques et des accusations de sorcellerie. Ce thème a suscité ces dernières années un intérêt notoire au sein de l'anthropologie amazonienne. Cet article propose une réflexion sur les appréciations et jugements proférés par les missionnaires concernant ces phénomènes. II souligne également la façon dont la cosmovision des indigènes convertis à l'évangélisme, bien loin de produire une rupture avec leur religiosité traditionnelle et l'acceptation d'une explication doctrinale chrétienne sur l'origine du mal et de la maladie, a débouché sur une interprétation complexe où s'entrecroisent les conceptions traditionnelles et «modernes» pour comprendre le principe et la présence du mal et du Malin dans le monde.

Mots clés : selva centrale, Ashaninka, missions, adventisme, enfants sorciers, chamanisme

\section{Living with the devil in house. The disease, child sorcery and violence among the asháninka from the Adventist missionary perspective}

\begin{abstract}
Since its establishment in the central jungle of Peru, to the 1920's, Adventist missionaries have constantly reported the permanency of a series of traditional rituals among the converted Asháninkas, which despite hard and constant criticism and missionary preaching, retain great vitality to the present day. Among these, the one that has been mainly reported — and then confronted by evangelization and pastoral action - has been the practice of "shamanism" and accusations of witchcraft accusat. Understanding that this issue tin the recent years has provoked interest within the Amazonian anthropology, we propose a reflection about the trials generated from the missionary perspective about this phenomena, noting how the worldview of indigenous converts to Adventism, beyond generating a break with their traditional religion and the acceptance of a Christian doctrinal explanation about the origins of the evil and disease, it has generated a complex interpretation of modern and traditional concepts to understand the principle and the presence of evil and the devil in the world.
\end{abstract}

Key words: central jungle, asháninka, missions, adventism, child sorcery, chamanism

\section{INTRODUCCIÓN}

El siguiente estudio tiene por objeto presentar las diversas maneras en que las acusaciones de hechicería y prácticas de curanderismo y shamanismo han sido reportadas e interpretadas por el adventismo dentro de las estaciones misioneras y comunidades nativas de la selva central peruana. En tal sentido, ofrecemos una 
revisión de la diversa bibliografía adventista que detalla la recurrencia de este tipo de fenómenos al interior de la sociedad asháninka desde una perspectiva misionera y pastoral; es decir, como el «enemigo» que debe enfrentarse dentro de la actividad evangelizadora y aculturadora. Del mismo modo, desarrollamos una explicación acerca de la permanencia de estas prácticas rituales dentro de las comunidades nativas y, sobre todo, dentro de la mentalidad religiosa de los grupos e iglesias adventistas las que, supuestamente, tendrían que haber asumido una ética y un compromiso cristiano y ascético.

Merced a nuestra investigación acerca de la historia misionera adventista en la selva central hemos recopilado una cantidad considerable de testimonios y relatos que describen la presencia de acusaciones de brujería y prácticas tradicionales, entendidas como paganas, desde la llegada de los primeros misioneros a la región y al interior de las actuales comunidades nativas. Estas son nuestras principales fuentes. Para el período histórico que va desde 1920 hasta, aproximadamente, 1950 hemos recurrido a las revistas denominacionales adventistas, con testimonios escritos exclusivamente por los misioneros norteamericanos - circunscritos a la zona del Alto Perené donde el misionado adventista centra sus actividades-. Para la segunda etapa, la fuente escrita, si bien sigue siendo mayoritaria, puede corroborarse con algunos testimonios orales de misioneros y asháninka conversos (en la mayoría de los casos, maestros o líderes de comunidades y organizaciones nativas), así como una serie de trabajos e informes provenientes de las ciencias sociales. Asimismo, en este período el área de estudio se expande, partiendo de la zona del Pichis, con algunos alcances de la región del Perené, el Gran Pajonal y el Unini (Alto Ucayali).

En los últimos años el antropólogo Fernando Santos Granero ha trabajado una serie de ensayos en los que propone una explicación a las acusaciones de hechicería infantil entre los arawak. Santos presenta este fenómeno como una manifestación de un acto mimético fallido, la interpretación desde la cosmovisión indígena de la actividad misionera, la violencia, la enfermedad y la muerte.

A fin de hacer didáctica nuestra presentación empezamos el texto ofreciendo una interpretación antropológica de la hechicería infantil y la brujería entre los asháninka, siguiendo con una periodificación de los brotes epidémicos y de violencia durante el siglo XX, marcados a partir de la presencia misionera adventista1. A continuación, reflexionamos acerca de la apreciación de este tipo de fenómenos dentro de las fuentes, partiendo de la subjetividad del autor de los testimonios y desde la explicación que se genera en la propia doctrina adventista sobre el origen del mal y la presencia del demonio en el mundo. Más adelante reconstruimos una serie de casos de «rescate de niños» acusados de hechicería y «manifestaciones demoníacas» presentes en las fuentes adventistas, para concluir con una interpretación tentativa acerca de la permanencia de este tipo de prácticas entre los grupos asháninka conversos al adventismo.

1 Al igual que Santos, en este trabajo no hacemos distinción entre brujería y hechicería infantil, puesto que para el caso asháninka ambos fenómenos presentan las mismas características. De igual modo, la cosmovisión —y las fuentes_ - adventistas no hacen distinción entre las prácticas del «chamán», el «hechicero» o el «brujo». 


\section{CONTEXTUALIZANDO LA BRUJERÍA INFANTIL}

Durante todo el siglo XX, período que tipifica las complejas relaciones entre la sociedad indígena y los agentes externos asentados en la Amazonía, las fuentes escritas y testimoniales han detallado distintos aspectos de la cultura y vivencia religiosa del pueblo amazónico. A los ojos de estos cronistas, interesados de diversa manera en su aculturación y asimilación a la sociedad nacional, hay un aspecto que, ya sea por lo exótico o por ser una clara evidencia del estado de «salvajismo» de estos grupos humanos, ha sido continuamente relatado en las crónicas y memorias de viajeros y misioneros. Se trata de las acusaciones de hechicería y la actividad de los «brujos» entre los asháninka y demás grupos étnicos de la selva peruana2. Para el caso de la selva central, desde las primeras descripciones de los misioneros franciscanos durante la «reconquista amazónica» republicana en la década de 1880, pasando por los informes de viajeros y misioneros católicos, evangélicos y adventistas, nos llegan relatos acerca de la recurrencia de estas prácticas rituales dentro del mundo indígena³.

Los asháninka, al igual que los demás grupos arawak de la selva central, consideran que la enfermedad se relaciona a la actividad de seres maléficos o demoníacos (máci) que habitan alrededor del mundo real. Asumiendo que existe un inestable equilibrio entre el mundo habitado por los hombres y el mundo espiritual, la enfermedad es entendida, esencialmente, como un estado originado por algunos actos humanos o de seres demoníacos que resulta de la interrupción del balance de poderes existentes (Elick, 1969: 211). Uno de estos agentes maléficos es el kamari máci (hechicero), quien causa la enfermedad por medio de la manipulación de materiales o restos corporales de una persona. Si, consultado frente al padecimiento de un miembro del grupo, el shamán indica que la pérdida de la salud se debe a un acto de hechicería, es necesario encontrar al culpable a fin de revertir el daño. El shamán, mediante una serie de procedimientos rituales, habrá de reconocer al autor del hechizo dentro de la misma comunidad. En este punto, la mayoría de autores concuerdan en afirmar que las acusaciones de hechicería recaen, por lo general, sobre un niño o algún miembro desprotegido de la colectividad (un huérfano, una viuda, una niña capturada en alguna correría) que no pueda defenderse de la imputación. Cuando la acusación apunta a un individuo adulto, se entiende que éste ha sido hechicero desde la niñez, sólo que ha evitado ser

2 El estudio bibliográfico de Santos indica que los grupos de lengua arawak en los cuales no se han reportado este tipo de prácticas rituales son los mashiguenga del Alto Urubamba y Alto Madre de Dios y los piro o yine del Bajo Urubamba (Santos, 2003: 161). Sin embargo, para el caso de los yine es posible relacionar las correrías y el tráfico de niños «huérfanos» con la presencia de acusaciones de brujería infantil (Camino, 1977: 123-140). Para el caso de la brujería entre los arákmbet de la selva sur peruana, véase Calífano \& Gonzalo (2004: 91-116).

3 La primera descripción conocida de este tipo de prácticas rituales entre los arawak de la selva central le corresponde al franciscano Bernardino Gonzáles (1880); mientras que entre los asháninka es anotado en 1895 por el viajero Olivier Ordinaire (Santos, 2005: 53). Para la descripción de la hechicería infantil, hemos tomado como referencia los trabajos de John Elick (1969) y Gerald Weiss (1975). 
detectado (Weiss, 1975: 292). Luego, los acusados son obligados a deshacer el hechizo por el shamán y la familia de la persona enferma. Si el enfermo alcanza alguna mejoría, los niños son sometidos a diversos ritos de purificación (dietas, vigilias, golpes) reconvertidos a «la esfera humana» y, posteriormente, liberados. Sin embargo, en muchas ocasiones el enfermo no mejora y fallece. En este caso los acusados son condenados a muerte y, según las fuentes, sometidos a terribles suplicios expiatorios llevados a cabo, la mayoría de las veces, por los familiares de la víctima, a manera de venganza o ajusticiamiento (Santos, 2005: 49-51).

Si bien la antropología amazónica, presente en la selva central desde la década de 1960, había anotado la persistencia de este tipo de prácticas rituales, no había podido elaborar ningún tipo de explicación, limitándose a describirlo y, en otros casos, a ocultarlo por el temor a que la prensa y opinión pública reforzase sus prejuicios acerca del «salvajismo innato» de los grupos indígenas amazónicos. Más aún, cuando se trataba de contextos en los cuales los indígenas luchaban por conseguir de parte del Estado y la sociedad nacional el derecho al autogobierno, el respeto a su territorio y el reconocimiento de sus propias organizaciones (Santos, 2003: 162).

El antropólogo Fernando Santos se ha dedicado en los últimos años a escribir una serie de textos relacionados a la violencia y acusaciones de brujería infantil entre los indígenas arawak de la selva central peruana, los cuales han sido comentados y reproducidos en diversas publicaciones especializadas. En ellos el autor propone una explicación sobre el origen de las acusaciones de brujería, basándose principalmente en fuentes recogidas entre los yánesha y los asháninka del Perené4. El análisis de las fuentes existentes, desde la época colonial hasta inicios del siglo XX, le permite sugerir que el mito que proporciona el fundamento para esta práctica ritual aparece en un contexto marcado por la crisis y la violencia, propio del choque cultural y biológico que significa la presencia colonial en su territorio y que se manifiesta, en la forma que ha sido descrita por todos los observadores desde fines del siglo XIX, recién desde el período de «conquista interna» republicana (Santos, 2005).

Según su explicación, la proliferación de este tipo de imputaciones sobre niños y niñas se evidencia durante coyunturas de crisis social, marcada por la presión externa, la violencia, el desplazamiento territorial y los brotes epidémicos. Encuentra su origen en una antigua leyenda de San Cristóbal y el Niño Jesús, relato introducido a la región con los primeros misioneros franciscanos que se

4 Evitando todo tipo de confusión clasificatoria basada en aspectos lingüísticos, utilizaremos el término asháninka para referirnos, indistintamente, a los nativos amazónicos conocidos anteriormente como «campa» (término actualmente en desuso debido a su connotación despectiva), que habitan la selva central. Están divididos en tres grupos: asháninka propiamente dichos (que habitan el Bajo Perené, Pichis, Ene, Tambo); los ashéninka (asentados en el Alto Perené y las tierras altas del Gran Pajonal); y, los notmashiguenga (que viven en las zonas del Pangoa, Sanibeni, Anapati y Kiatari). Por supuesto que el uso de esta clasificación se limita a las zonas en las cuales el adventismo ha tenido presencia misionera y que son rescatados en los testimonios, entre las cuales destacan el Alto Perené y Perené medio, el Alto Pichis (ríos Azupizú, Nazaratequi y Neguachi) y el Alto Ucayali (río Unini). 
asentaron en Chanchamayo y el Perené desde el siglo XVI. Apropiada mediante magia mimética durante la Colonia, la historia del «santo protector de las plagas» fue invertida en la cosmovisión asháninka, haciendo aparecer a su personaje como un ser antropófago que, acompañado de su diabólico hijo, causaba maleficios y la muerte de la gente. De este modo, la posibilidad de que los niños pudiesen ser herederos del poder maligno de enérgicos hechiceros ha sido reafirmada, desde finales del siglo XIX, con la presencia de brotes epidémicos que, en algunos casos como el sarampión, han afectado mayoritariamente a los adultos.

Esta habría sido la causa del ensañamiento de los shamanes arawak sobre los niños acusados de brujería. Ante la incomprensión de las epidemias y la muerte recurrente, los nativos habrían relacionado, mediante una interpretación mimética fallida, la enfermedad y la resistencia de los niños y jóvenes a la misma, acusándoles de ser los causantes de la enfermedad (el daño). Una vez enajenados simbólicamente del grupo social —reconocidos ontológicamente como distintos y maléficos - se efectuaba la ejecución del castigo.

Más adelante, a partir de la presencia cada vez mayor de colonos y comerciantes en el territorio asháninka, empieza a hacerse común otro tipo de solución al problema de los «niños brujos»; es decir, la venta o la entrega voluntaria de parte de los padres que quieren evitar la muerte de sus hijos. Dentro de este contexto de violencia, los misioneros también aparecen como una alternativa al asesinato expiatorio de niños, manejando esta práctica a partir de sus propios intereses, promoviendo el «rescate de niños» 5 , actividad que con los años alcanzaría carácter orgánico dentro de los modelos de evangelización y civilización misioneras, especialmente franciscanas. Se ha anotado con anterioridad que la motivación institucional franciscana para el establecimiento de las misiones de Puerto Ocopa

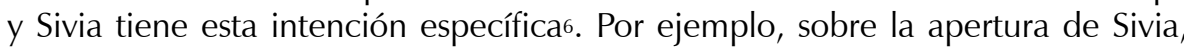
en el río Apurimac, escribe el fraile Francisco Arroyo, hacia diciembre de 1935:

«El objeto de la fundación de Sivia (...) es la adquisición de niños campas con el propósito de cristianizarlos (...) hay algunas familias campas que se han logrado para la civilización, y debido a la escasez de medios con que cuenta la misión, es que no se han logrado más (...) En la actualidad son como unos 20 muchachos campitas que se están educando en la misión, corriendo a costa de esta los gastos de manutención y vestidos» (Arroyo, 1936: 967).

Por supuesto que estos «rescates» eran destacados de manera muy intensa por los propios misioneros. En un sentido, la publicidad que este hecho les representaba, afianzaba sus solicitudes de mayor financiamiento y recursos, tanto al Estado como

5 «Si los padres de un niño acusado de brujería en contra de alguien fuera de la familia no desean que sea asesinado es posible, bajo cierto riesgo, entregar al niño a un misionero, en caso el niño por sí mismo no intentó escapar a una misión. Una alternativa aceptable a la ejecución, cuando los ánimos no están muy inflamados, es la venta del niño a un colono caucásico, con lo que se elimina de forma efectiva la amenaza sobre la comunidad mientras que al mismo se proporciona un beneficio adicional en forma de mercancías obtenidas de la venta» (Weiss, 1975: 293).

6 Puerto Ocopa, fundado en 1920, fue establecido como punto de avanzada misionera por su ubicación estratégica en el territorio asháninka y porque estaba fuera del control efectivo de la 
a sus propias instituciones7. Si bien, para el caso adventista, no hemos encontrado en las fuentes algún indicio que nos haga suponer que el «rescate de niños» era una práctica institucionalizada por su organización; es decir, que existieran fondos específicos para el intercambio, era muy probable que los guerreros indígenas dedicados al tráfico de esclavos hayan interpretado a las misiones adventistas de la misma manera que entendían sus relaciones con los franciscanos, terratenientes y comerciantes locales.

\section{ENFERMEDAD Y VIOLENCIA RELACIONADAS A LAS MISIONES ADVENTISTAS}

Un elemento significativo dentro de la reconstrucción de Santos (2005) sobre los brotes de epidemia y violencia entre los asháninka es la presencia de las misiones adventistas en el Perené. El adventismo llega a esta región hacia 1921, con el inicio del misionado del norteamericano Ferdinand Stahl, quien se establece en la zona de Metraro, iniciando un proceso de evangelización basado en la constitución de estaciones misioneras en las que se concentran numerosas familias nativas, ofreciéndoles una serie de servicios, en especial educativos y sanitarios. Sin embargo, como ya se ha destacado anteriormente, los recurrentes brotes epidémicos que han sometido a la región del Perené durante las primeras décadas del siglo XX han sido significativamente mortales en estos asentamientos misioneros8. Resumiendo mucha de la información de sus anteriores investigaciones, John Bodley indicaba el impacto que ha tenido la presencia colona y misionera entre los asháninka:

«Las tasas incrementadas de mortandad debido a enfermedades epidémicas introducidas por personas provenientes de fuera del lugar, sin duda alguna, han continuado siendo la principal causa de despoblación en las áreas campa durante los últimos 100 años (...) Al momento de considerar solamente los casos de muerte debido a causas conocidas, aproximadamente un $75 \%$ puede asignarse a enfermedades epidémicas» (Bodley, 1981: 11).

Hasta donde conocemos, podemos destacar tres ataques epidémicos al interior de las agrupaciones adventistas en el Perené. La primera referencia se sitúa alrededor del año 1928, durante la movilización mesiánica relacionada al discurso profético

Perene Colony, empresa con la que los misioneros habían tenido un distanciamiento desde la década anterior. Ese mismo año se estableció una escuela «(...) para la formación cultural y religiosa de los niños campas, los cuales eran también utilizados en las faenas del campo» (Ortíz, 1978: 171172). Con el fin de obtener recursos para el «rescate de niños salvajes», los misioneros contaban con el apoyo de un grupo de colaboradores, que financiaban la publicación de la revista Florecillas de San Antonio a manera de suscriptores. Hacia 1929, informaba «Sor María Teresa», que la escuela tenía 87 internados: 44 niños y 43 niñas (Sor María Teresa, 1929: 21-23).

7 Sin embargo, esta práctica fomentó con los años el mismo tráfico que se criticaba y buscaba eliminar. Muchos jefes indígenas encontraron en el secuestro de niños y jóvenes la mejor manera de adquirir bienes manufacturados dentro de las misiones que, gustosas, ofrecían estas herramientas a manera de intercambio por la mercancía humana.

8 Véase La Serna Salcedo (2007: 82-90). 
de Ferdinand Stahl. Para ello nos basamos en la información recogida dentro de la investigación de Bodley quien anota que cientos de nativos habrían muerto a causa de sarampión y otras infecciones dentro de los esporádicos asentamientos a lo largo del Bajo Perené y, al parecer, en el Tambo, debido al prolongado período de permanencia en espacios reducidos y con alto nivel de hacinamiento (Bodley, 1970: 115)9.

Entre abril y mayo de 1928, V. E. Peugh, presidente de la Unión Incaica, y Ferdinand Stahl realizaron un viaje de proyección misionera en el territorio asháninka. Partiendo de Chanchamayo recorrieron los ríos Perené, Tambo y Ucayali, finalizando en la ciudad de Iquitos. Durante este viaje ambos misioneros destacaron la existencia de una serie de agrupaciones establecidas a través del Bajo Perené y el Tambo, asemejando el modelo de asentamiento de la misión de Metraro. El primer asentamiento que visitaron estaba dirigido por el jefe Manari y se encontraba en la zona de Cascadas, en el Perené medio10. En esta agrupación, que según la apreciación del misionero reunía algunos cientos de nativos, se describen una serie de afecciones que presentaban los nativos y los servicios médicos que fueron aplicados por los misioneros:

«Los dos misioneros miraron a su alrededor asombrados. Habían visto enfermedades tropicales, pero no estaban preparados para las terribles cosas que se ofrecieron a su vista aquel día en esa aldea: malaria, úlceras tropicales, llagas de toda clase. La mayoría de las personas parecían consumidas (...) Pero lo más espantoso de todo estaba en sus ojos. Estaban hinchados y los párpados pegados. Muchos estaban completamente ciegos y evidentemente sufrían agudos dolores.

Habían pensado pasar un día como máximo en cada aldea. En las cascadas quedaron dos semanas, tanto había que hacer. Los días se sucedían con abrumadora rutina, curando enfermos. Cada mañana empezaba de la misma manera» (Booton, 1958: 101).

Continuando su recorrido, describían dos grandes agrupaciones de nativos asentados en el río Tambo, con campos cultivados y construcciones para una escuela. La primera agrupación consta de unas 200 personas y era liderada por el jefe José Carlos, mientras la segunda constaba de alrededor de 400 individuos y era encabezada por el jefe Umpicari (Yum Pecari) (Peugh, 1929b: 12-13). En este último grupo, los misioneros también dedicaron algunos días a la prestación de servicios médicos entre los nativos (Booton, 1958: 102).

9 Sobre ello, las fuentes adventistas no hacen mayores comentarios, lo que podría generar algún tipo de suspicacias. Empero, es muy probable que este hecho haya ocurrido debido a las condiciones generales de exaltación y aglomeración de la población asháninka por la presencia misionera carismática.

10 «En diferentes momentos en el pasado, muchas de las personas de Cascadas pasaron algún tiempo en la Misión de Metraro y, entre tanto, aceptaron la verdad. Volvieron a sus pueblos y enseñaron a su gente las verdades que habían aprendido. Como resultado de la labor de estos misioneros informales, encontramos que un pueblo entero cambió. Todos habían abandonado el consumo de tabaco, bebidas alcohólicas y cocaína (...)» (Peugh, 1929a: 16). 
Estos hechos concordaron con un período de expansión del adventismo en la Amazonía peruana. Desde Metraro se impulsó el envío de misioneros nativos al interior del Perené y el Tambo. Esto conllevó al establecimiento de la misión de Cascadas en el Perené medio y de Santoriani en el Tambo. Asimismo, se estableció la Misión del Alto Amazonas con el objetivo de administrar toda la actividad misionera en la región, tanto entre indígenas como entre la población colona. El incremento de la actividad misionera adventista empezó a generar enfrentamientos con los misioneros católicos, hacendados y comerciantes, quienes fomentaban una reacción negativa contra la presencia adventista. Desde Iquitos se publicaron acusaciones contra estos «protestantes»:

«Hasta hace poco era llamado a comparecer ante las autoridades casi todos los días para responder a cargos como asesinato, incitar a los indios a matar a los hombres blancos, o a la rebelión. La última vez que fui llamado a responder a la acusación de haber distribuido octavillas por miles en contra del presidente» (Stahl, 1929b: 20)11.

Tal situación habría condicionado, un par de años después, el traslado de las estaciones misioneras de Cascadas y Santoriani a la zona de Sutziki, en el Alto Perené, hacia donde se trasladó un importante número de neófitos de las antiguas misiones ${ }^{12}$. Sin embargo, el establecimiento del nuevo centro misional no estuvo exento de conflicto. William Schaeffler anotó la oposición que encontraron de parte de varios grupos indígenas de los alrededores de Sutziki:

«Mientras que muchos habían estado esperando durante un largo tiempo la llegada del misionero blanco, quien viviría en su territorio, abriendo una escuela grande y tratando a sus enfermos, otros se enojaron mucho con la noticia (...) se mostraron muy hostiles con todos los indios que estaban a favor de la misión» (Schaeffler, 1931: 3)13.

El misionero Schaeffler describe, además, manifestaciones de rechazo a la presencia cultural foránea — personificada en la figura de los misioneros y la Colonia del Perené-, movilización liderada por algunos shamanes asháninka:

«A varias horas bajando de Sutchiqui los enemigos de la misión se reunieron para construir una misión para adorar al diablo por sí mismos. Llamaron a su médico brujo y le pidieron que haga aparecer al diablo (...) Más tarde

11 Asimismo, Stahl destaca el encarcelamiento de Olisas, misionero piro formado en Metraro, maestro en la Misión del Tambo, quien fue acusado de asesinato por grupos de hacendados opuestos a la labor misionera. Véase Stahl (1929a: 18-19).

12 Sobre el conflicto en Cascadas, informaba H. D. Lundquist: «(...) debido a la persecución de una parte de las autoridades influenciadas por la iglesia establecida, nuestra obra fue movida a un lugar sobre el río Perené (...) Este lugar es llamado Zutsiki y hemos trasladado la obra allá desde aproximadamente 1929» (Lundquist, 1938: 2-3).

13 En estas líneas describe la amenaza de un jefe yánesha quien, junto a un grupo de 20 guerreros, intenta impedir el establecimiento de la misión de Sutziki, pero que, sin embargo, es repelido por los guerreros asháninka que acompañan al misionero desde el Tambo. Véase también Montgomery (1933: 22). 
me dijeron que un espíritu se les había aparecido y les había animado a continuar sus viejas maneras de beber, asesinando y teniendo muchas mujeres y manteniéndose lejos de nuestra misión sus indios» (1931: 3)14.

Más adelante, una segunda epidemia diezmó, hacia 1933, a los neófitos asentados alrededor de la estación de Sutziki15. Sobre este hecho tenemos el testimonio de William Schaeffler, para la época director de la estación de Sutziki, quien informó sobre las devastadoras consecuencias que tuvo la propagación de la epidemia de sarampión en el Alto Perené:

«Durante octubre y noviembre del año pasado [1933] toda la selva virgen al este del Perú fue visitada por una epidemia de sarampión. Nuestra misión en el río Perené también sintió sus devastadores efectos.

(...)El número de enfermos aumentó increíblemente y muchos murieron. Pero lo peor ocurrió cuando Shanqui, el jefe principal, también se enfermó. Él había ayudado a mi esposa por semanas en su rutina diaria con los enfermos desempeñándose como traductor. Una vez que le subió la fiebre empezó a delirar y en un momento de descuido llamó a su gente y los llevó al agua, donde todos, a pesar de su fiebre alta, se dieron un baño. El resultado fue una neumonía en prácticamente todos los casos y casi todos los hombres de la tribu de Shanqui murieron como resultado de esto. De más de 400 hombres que vivían en la misión más de 300 se enfermaron al mismo tiempo. Mi esposa y yo estábamos muy desgastados a causa del trabajo ininterrumpido con los enfermos. Los pocos hombres que todavía estaban hábiles hacían más de lo que podían cavando tumbas y llevando agua fría y leña, así como alimentos para los enfermos. El número de tumbas aumentaba cada día (...).

Sólo cuando la epidemia había pasado y la vida de la misión volvió a su acostumbrada rutina, tuvimos realmente una comprensión completa de los estragos causados por la enfermedad. La tribu de Shanqui casi desaparece por completo. El segundo jefe, Victoriano, perdió a su mujer y a su único hijo a la misma hora y ellos se encuentran enterrados lado a lado en la misma tumba. La villa está llena de huérfanos y no hay una persona que no esté de luto por alguien. El número total de muertes en esta estación totaliza alrededor de ciento treinta y en la subestación de Tontoarini (sic) cerca de doscientos cincuenta neófitos han muerto. Cuando la epidemia empezó teníamos una clase bautismal de treinta y cinco y al final solo nueve continuaban vivos» (Schaeffler, 1934: 7).

$14 \mathrm{Al}$ mismo tiempo, la campaña de descrédito de los hacendados locales contra la misión y la Colonia del Perené se dejó sentir entre los propios neófitos de Sutziki, al punto que, durante el año de 1930, los misioneros no lograron movilizar a ningún nativo para trabajar en las plantaciones de la cafetalera. Véase Thompson (1931: 5).

15 Frederica Barclay afirma que de los 300 nativos que vivían en la misión, unos 120 habrían muerto a causa de una epidemia de sarampión (Barclay, 1989: 126). 
Estas cifras pueden ser corroboradas por la información que se rescata de un informe de F. E. Bresee, miembro de la Unión Incaica16:

«El año pasado [1933] las tribus de indios del Perené fueron visitadas por una epidemia de sarampión (...) tres enfermeras entrenadas de nuestra organización trabajaron durante semanas combatiendo al temible visitante. Donde nosotros pudimos alcanzar alguna ayuda el índice de mortalidad era sólo de veinticinco por ciento comparado con un índice de mortalidad del setenta y cinco a cien por ciento donde no llegó ninguna ayuda. Grandes agrupaciones de indios en lugares no contactados a lo largo de los ríos fueron en muchos casos casi devastados, mientras en algunas instancias fueron completamente borrados» (Bresee, 1934: 7).

Esta impactante tasa de mortandad, repetida en la mayoría de las agrupaciones asháninka del Alto Perené, originó una serie de levantamientos de nativos contra la presencia de misioneros y la Colonia del Perené, entendiendo que eran los causantes de la enfermedad y la devastación demográfica17. Al mismo tiempo, Santos (2005: 54), reconoció un incremento en las acusaciones de hechicería infantil dentro esta coyuntura18.

Un tercer brote epidémico ocurre hacia 1939. Sobre este caso, se rescatan los resultados de la investigación médico-sanitaria en la Colonia del Perené elaborada por Máximo Kuczynski Godard, del Instituto de Medicina Social de la Universidad de San Marcos. El autor analiza la situación de los indígenas asentados en las misiones adventistas de Sutziki y Kimariaki, anotando 72 casos de sarampión entre los habitantes de Sutziki, de los cuales 5 fallecieron19. Este hecho fue relatado de manera optimista por el médico, quien aduce que la baja mortandad sería un «resultado bastante favorable que se debe al cuidado ejemplar que se ha prestado a los enfermos. Debemos contar ahora con una inmunización bastante completa de la población chuncha, lo que va a cambiar en años futuros» (Kuczynski Godard, 1939: 28).

16 La Unión Incaica era el órgano administrativo de la iglesia adventista en Perú, Bolivia y Ecuador.

17 Los asháninka habrían interpretado que «el sarampión ha[bía] sido traído a propósito por los peruanos para matar a los 〈indios»» (Carta del misionero de Sutziki a la Colonia, 17 de noviembre de 1933; citado por Barclay, 1989: 127). Incluso, según apunta Barclay, los nativos obligaron al «cierre» de la misión de Sutziki, dando muerte a algunos de los neófitos de las misiones (Barclay, 1989: 127). Este dato, no obstante, era incorrecto. Sutziki no fue cerrada y mantuvo sus actividades a pesar del catastrófico nivel de mortandad alcanzado. No pasó lo mismo con sus subestaciones, como Tsotani o Tontoarini, que fueron devastadas por la epidemia. Véase Schaeffler (1934: 7).

18 Schaeffler (1934: 7) anota el asesinato de niños en algunas agrupaciones no adventistas en el Perené: «en otras tribus los indios arrojan todos los bebés al río, porque no había ninguna mujer que se encargue de ellos». Ahora, nosotros podemos asociar este hecho con la práctica de hechicería infantil. En una misiva al administrador de la Colonia, Schaeffler repite esta apreciación «como consecuencia de la epidemia grupos de salvajes matan enfermos y menores de edad que se encuentran sin protección en las playas» (Carta de Schaeffler a Valle Riestra 17 de noviembre de 1933; citado por Barclay, 1989: 127).

19 En una publicación de la colonia angloamericana en Lima se indicaba sobre la epidemia de sarampión de 1939: «J.C. Ruskjer, con su pequeña fuerza de ayudantes han salvado las vidas de muchos nativos durante una severa epidemia de sarampión. Esta enfermedad es casi siempre fatal entre los indios, sin embargo de más de cien casos, sólo tres muertes han sido reportadas» (Anónimo, 1939: 10). 
De igual modo, sus estudios brindan información que permite destacar la caída demográfica en toda la zona del Alto Perené y la numerosa presencia de niños y huérfanos dentro de las estaciones misioneras adventistas de Sutziki y Kimariaki:

«El miedo supersticioso de la brujería amenaza la vida de muchos niños. A esto, así como a las devastaciones por ciertas epidemias, como el sarampión en los años 1933 y 1939, se debe la despoblación notable de toda la región ocupada por los Campas. La mortalidad infantil, ya grande por las enfermedades regionales, aumenta hasta tal grado, que estas tribus se encuentran en una situación precaria» (Kuczynski Godard, 1939: 25)20.

Fuera del Perené, también se conoció la ocurrencia de ataques epidémicos en el valle del Pichis relacionados a la presencia misionera. El caso más significativo sucedió hacia 1965 cuando un nuevo brote de sarampión afectó a los asháninka del Azupizú, en el Alto Pichis. Sobre este hecho tuvimos información de los sucesos acontecidos en la misión de Miritiriani, en el Azupizú (Alto Pichis), donde se agrupaban algunas familias reunidas alrededor de una escuela que, según las fuentes adventistas, tenía unos 30 alumnos y estaba dirigida por un maestro asháninka. En esta ocasión los nativos que comercializaban productos en Puerto Bermúdez contrajeron el sarampión y luego trasmitieron la enfermedad en Miritiriani. A pesar del esfuerzo sanitario adventista, que incluía el uso de una avioneta de la institución, 6 indígenas fallecieron (Case, 1965: 20-21). Sobre este hecho, escribía John Bodley:

«En 1965 cinco indios campa murieron de sarampión en la Misión Adventista de Miritiriani incluso cuando se disponía de pronta ayuda médica. A menudo, el temor a tales epidemias es atribuido como razón para dejar una misión y otras áreas de floreciente contacto con el exterior. Como medida de precaución adicional, se observa de cerca a las personas foráneas que visitan grupos aislados y se interroga para tener certeza de que no son portadoras de enfermedades» (Bodley, 1981: 11).

Si bien desde su establecimiento en el Alto Perené, los misioneros adventistas logran entablar buenas relaciones con una serie de líderes tradicionales -lo que les ha permitido iniciar exitosamente su actividad misionera-, existen referencias sobre una serie de jefes nativos que han ofrecido resistencia, violenta y simbólica, frente a las intenciones de los misioneros de expandir su influencia dentro de su grupo y territorio. Si bien las fuentes resaltan los casos en que los líderes aceptan a los misioneros, de manera abierta o implícita, es posible rescatar algunos casos en los que estos asumen una actitud confrontacional y beligerante.

20 El autor indica que, al momento de su primera visita al Perené (hacia 1938), encontró a 220 individuos viviendo en Sutziki, de los cuales 135 eran mayores de 13 años y 87 eran menores de esa edad. En Kimariaki encontró a 65 personas, de las cuales 15 eran niños o semiadultos huérfanos. En una visita posterior (1939), encontró que de los 82 niños que vivían en Sutziki, 37 eran «huérfanos completos». Estas cifras permitieron confirmar la tesis de Santos que relacionaba la incidencia epidémica con el crecimiento de las acusaciones de brujería y al consecuente incremento de niños en las misiones adventistas que, a los ojos de los foráneos, aparecían como zonas de refugio para las agrupaciones asháninka aledañas a la misión. 
En este sentido, el enfrentamiento entre el liderazgo tradicional y la misión se refería a la pérdida de influencia que ejercía un importante dirigente a causa de la competencia misionera. Recordemos que los adventistas otorgaban una serie de servicios y bienes que, a los ojos de muchos líderes indígenas, sobre todo los que tenían alguna relación mercantil con hacendados o comerciantes locales, eran bastante apreciados. Además, en la zona de Metraro y el Alto Perené, la misión iba a asumir la función de movilizar la mano de obra asháninka hacia las plantaciones de la Colonia del Perené (Barclay, 1989).

Para el adventismo la misión tiene un sentido de «cruzada» contra el paganismo - entendido como la presencia y predominio del demonio en el mundo-, reconocido en muchas de las manifestaciones rituales indígenas anotadas por los misioneros: el asesinato por acusaciones de brujería y las ceremonias con bailes y consumo de psicotrópicos y estimulantes. En este sentido, la influencia que ejercen los shamanes dentro de su grupo se verá disminuida, tanto por el uso de medicinas de parte de los misioneros, como por la propagación de nuevas enfermedades como el sarampión, la neumonía y la viruela que arrasarán, durante brotes epidémicos, a gran parte de la población del Alto Perené. Esas afecciones son entendidas como «enfermedades de los blancos o peruanos», frente a las cuales los detentores del conocimiento tradicional no tienen un paliativo efectivo, más que el rechazo, real y simbólico, de la cultura impuesta por los foráneos.

Durante las primeras dos décadas de actividad misionera en el Perené, hemos encontrado numerosos enfrentamientos entre los adventistas y los líderes tradicionales indígenas. Así, por ejemplo, hacia 1923, Ferdinand Stahl describe la manera en que los shamanes promueven la desmovilización de un grupo importante de asháninka originarios del Ucayali, quienes son atraídos por las noticias que se expanden en la región acerca de las actividades de los misioneros de Metraro. En este caso los misioneros indican que estos shamanes les acusan de agrupar a la gente con el fin de asesinarlos (Stahl, 1923b: 22). Dentro de un contexto de conflictividad latente, es natural que la expansión del adventismo, más allá del Alto Perené, acrecentase estas confrontaciones. A continuación, describimos un caso que resalta el conflicto entre el líder tradicional y los misioneros.

\section{1. El caso del jefe Zárate}

Andrés Zárate vivía en Metraro y era uno de los jefes asháninka más importantes del Alto Perené. Era, asimismo, un «capitán»; es decir, un líder que movilizaba a su gente para trabajar en las plantaciones de la Colonia del Perené. Con los años se convirtió en uno de los más fieles colaboradores de la empresa cafetalera, al punto que, desde 1914, teníamos noticias suyas. Hacia julio de ese año fue Ilevado de «paseo» a Lima por el administrador de la Colonia, Víctor Valle Riestra, a fin de acabar con los temores que habían producido en la opinión pública nacional los levantamientos indígenas en la Vía del Pichis y que, según aparecía en la prensa capitalina, amenazaba con incorporar en su sublevación 
a todos los grupos étnicos amazónicos a fin de «arrojar al hombre blanco de su territorio» (Anónimo, 1914: 1).

Desde el ingreso de Ferdinand Stahl al Perené fue uno de los primeros líderes que colaboró con entusiasmo con los planes del misionero. Movilizó a su gente para abrir trochas y rozar el campo que serviría para establecer, hacia agosto de 1922, la primera estación misionera adventista en la Amazonía peruana: la misión de Metraro. Si bien nunca se asentó con su familia en la misión, realizó numerosas visitas, participando de las celebraciones religiosas y solicitando medicinas para su familia. Todo indicaba que se convertiría en un importante soporte para la obra misionera.

Sin embargo, este entusiasmo inicial se tornaría pronto en una amenaza para los misioneros y neófitos de Metraro. Zárate se negó a continuar colaborando con la misión y se convirtió en uno de los principales opositores a la labor evangélica. Al parecer, su oposición fue más que efectiva ya que los misioneros, en especial el prolífico Ferdinand Stahl, le dedicaron numerosos comentarios dentro de sus testimonios publicados en revistas denominacionales. El más interesante es aquel que le dedicó Stahl con motivo de su fallecimiento: «Zarate is Dead» (Zárate ha muerto). Esta nota comenzó con una descripción de las relaciones cordiales que existieron entre la misión y el líder nativo una vez establecida la misión de Metraro:

«Cuando establecimos nuestra estación misionera, hace unos seis años, él disponía de un gran grupo de personas en la región del Alto Amazonas. Al principio parecía estar complacido de que hubiéramos establecido esta misión, y ordenó a su gente abrir un camino para nosotros a través de la densa selva hasta el lugar donde nuestra misión iba ser localizada, y nos ayudó en todo lo que pudo» (Stahl, 1928: 20).

Podemos entender el entusiasmo inicial de Zárate frente a la misión si analizamos los beneficios que le significa el establecimiento de este extranjero en su territorio para el reforzamiento de su legitimidad como líder local. Más allá de la propuesta religiosa, la posibilidad de acceder a servicios educativos y sanitarios para un jefe como Zárate, para este momento bastante integrado a la lógica mercantil de la Peruvian, es sumamente provechosa. Del mismo modo, la ubicación estratégica de Zárate en Metraro (dentro del circuito comercial-ritual del Cerro de la Sal) habría podido reforzarse gracias a los «servicios» que otorga la misión establecida en su área de influencia21.

Sin embargo las fuentes indican que tiempo después Zárate se convirtió en el más férreo enemigo de la misión, amenazando a las familias que se relacionaban con los misioneros y promoviendo la deserción de los neófitos de Metraro. A opinión de Stahl, fue el arraigado deseo de satisfacer sus «malos hábitos y vicios»lo que

21 Cabe destacar que ya para 1914 el administrador de la Colonia, Valle Riestra, había deslizado la posibilidad de establecer una escuela para los nativos que laboraban en sus plantaciones. Véase Anónimo (1914). 
originó esta actitud22. Sobre la oposición de Zárate a dejar de lado sus costumbres y usos tradicionales, comentará más adelante que:

«(...) Cuando oyó nuestras enseñanzas que debemos renunciar a todos nuestros malos hábitos para convertirnos en discípulos de Cristo, empezó a separarse de nosotros. Traté de explicarle que Dios prohíbe solo las cosas que son perjudiciales para nosotros, pero él respondió: «Dios hizo la planta de coca, y cuando masticamos las hojas, no sentimos ni frío ni calor; no tenemos ni hambre ni sed y no nos cansamos (...) Nos dices que no usemos masato (bebida nativa), pero Dios hizo la planta de la yuca y el plátano para que nosotros hagamos esta bebida»» (Stahl, 1928: 20).

Por otro lado, es claro que el incremento de la influencia de los misioneros sobre la población indígena entraba en contradicción con los propios intereses del jefe Zárate, quien, por ejemplo, perdía la capacidad de movilizar individuos para las actividades agrícolas de la Colonia. Este habría sido otro de los motivos que generó su enfrentamiento con los misioneros de Metraro. Poco a poco su alejamiento se hizo más visible, y las amenazas hacia los nativos que continuaban participando de las actividades de la misión se hicieron más constantes. Sobre ello, continúa el relato de Stahl:

«Durante un tiempo parecía que iba a obtener la victoria, pero cuando vio que la misión estaba ganando influencia entre su gente, se puso celoso, y tomó posición en contra de la misión y de todos los que asistieron a las reuniones. Envió a muchos de sus hombres armados a atacar a nuestros creyentes y amenazaron con matarlos. Aunque muchos continuaron viniendo a las reuniones, era evidente entre ellos un lamentable nerviosismo y se escabullían furtivamente como si esperaran un ataque repentino» (Stahl, 1928: 20).

Si bien Zárate había intimidado a los neófitos y al misionero — -legando alguna vez a apersonarse a la estación en actitud beligerante con un grupo de guerreros-, nunca llegó a hacer efectiva su amenaza, limitándose a mantener a su grupo al margen de las actividades de la misión. Luego de su fallecimiento, hacia 1926, las presiones contra la misión de Metraro habrían cesado, al tiempo que su propio grupo familiar empezaba a participar de las actividades religiosas y asumiendo los misioneros la responsabilidad de movilizar a los nativos a las plantaciones de la Colonia, función tradicionalmente asumida por el «capitán» Zárate23.

${ }^{22}$ Y no habría de estar muy lejos de la verdad. Insistentemente se ha resaltado el espíritu de libertad que existe entre los indígenas amazónicos, situación que ha condicionado las relaciones entre éstos y la sociedad colonial y nacional, más aún cuando nos referimos a proyectos misioneros. Hay que reconocer que el sentido de conversión promovido por los adventistas, al igual que las demás organizaciones religiosas que desarrollan el sistema de «misión», promueve la aculturación y la «desindianización». Más aún en el caso del adventismo, que promueve una ética ascética bastante rígida, prohibiendo todo tipo de estimulante como el alcohol, el tabaco, la coca y el baile. Esta limitación ataca directamente a la jefatura del grupo étnico a quienes, además, se les prohibe la poliginia.

23 Sobre la historia de Zárate y su enfrentamiento con la misión de Metraro, véase Ramos (2005: 4041), Stahl (1932: 53-55). 


\section{LA HECHICERÍA Y EL SHAMANISMO VISTOS DESDE EL ADVENTISMO}

Debemos anotar que en la primera etapa del proyecto misionero — que situamos entre principios de la década de 1920 e inicios de la de 1950 - , las fuentes adventistas, en su gran mayoría crónicas y relatos escritos por misioneros norteamericanos, son bastante escépticas frente a las prácticas de shamanismo y las acusaciones de brujería, limitándose a exponer estos fenómenos «desde afuera», como características del estado de «salvajismo» e «ignorancia» en que viven los nativos que son objeto de su actividad misionera.

Más adelante, a partir del texto del pastor argentino Pérez Marcio (1953), encontramos un nuevo tipo de acercamiento en el que se desliza la posibilidad de que, tanto misioneros como maestros adventistas, tengan que elaborar algún tipo de interpretación a fenómenos que no pueden ser esclarecidos «objetivamente» y donde sean necesarias explicaciones basadas en la cosmovisión adventista; es decir, en las cuales aparece la clara confrontación - hasta cierto punto maniquea- existente entre el bien y el mal (Pérez Marcio, 1953)24. Es significativo el hecho que en esta segunda etapa identificamos fuentes mucho más diversas, donde los testimonios llegan de observadores de origen distinto. Ya no es solo la versión del misionero norteamericano, sino que conjuntamente aparecen las versiones de misioneros peruanos, observadores no adventistas dentro de las misiones y, por último - y lo más destacable_-, la visión de los propios nativos conversos quienes aparecerán dando su opinión acerca de la recurrencia de estos fenómenos.

En este sentido, vale destacar la procedencia y visiones de los misioneros con respecto a la sociedad y cultura indígena, como ya lo anota Jeremy Narby, desestimando la percepción común de los investigadores que entienden a los misioneros como un grupo homogéneo, en el sentido de su rechazo y desprecio por la cultura tradicional asháninka25. Es importante reconocer los distintos contextos en los que desarrollan su actividad, así como la formación de cada individuo que se dedica al misionado en la Amazonía. Desde esta perspectiva, podemos apreciar diferentes formas de entender la cultura y de plasmar los testimonios en las fuentes. A fin de hacer más didáctica nuestra explicación, dividiremos

24 Presentamos este texto como una especie de «bisagra» entre dos formas de entender las prácticas rituales tradicionales (shamanismo y acusaciones de brujería) dentro del adventismo. Ambas visiones aparecen, en distintos momentos, dentro de este testimonio misionero.

25 Este autor hace una clara distinción entre dos misioneros que han dejado testimonio de su actividad entre los asháninka, los que, a su vez, marcan posiciones extremas en cuanto a su percepción de la cultura nativa. De un lado, presenta a John Elick, quien aparece como respetuoso de las costumbres y conocimientos tradicionales; mientras que, en la otra orilla, ubica a Alejandro Bullón, quien maneja una idea del «progreso civilizatorio» innato a la actividad misionera, razón por la cual presenta a los nativos como «gente bruta e ignorante que ni sabe trabajar ni cómo ayudarse a salir del estado de embrutecimiento y quienes, por lo tanto, merecen compasión y ayuda» (Narby, 1989: 88-90). 
las descripciones de fuentes siguiendo los dos grandes momentos demarcados anteriormente, dependiendo del tipo de observador que genera la descripción.

\section{1. «Médicos-brujos» y acusaciones de hechicería como manifestación del pensamiento salvaje 26}

Durante el primer período las fuentes describen las prácticas rituales tradicionales como manifestaciones del estado de naturaleza y superstición en que se encuentran los indígenas antes de ser conversos y asumir la influencia religiosa adventista («conocer al verdadero Dios»). Según la perspectiva de los misioneros, quienes desvirtúan por completo la actividad evangelizadora precedente realizada por los franciscanos, los asháninka no habían recibido ningún tipo de influencia cultural o religiosa antes de su llegada, en tal sentido, todo rito es juzgado como paganismo o, lo que es lo mismo, como manifestación del demonio en la vida de los hombres:

«Es una cosa terrible estar sin un conocimiento del Dios verdadero. El resultado, como hemos visto en la vida de estas personas, es que están abandonados al vicio y la sensualidad. Son adictos al uso del tabaco, usan plantas narcóticas y bebidas alcohólicas, y gastan gran parte del tiempo en bailes salvajes. Son ignorantes de todas las leyes de salud e higiene, y están sujetos a las ataduras de la terrible y mortal superstición» (Stahl, 1926: 14).

Desde los primeros escritos misioneros sobre el Perené aparecen referencias a la actividad de los médicos brujos y acusaciones de brujería. La primera referencia que tenemos fue publicada en The Advent Review and Sabath Herald, en noviembre de 1923. En esta nota, Ferdinand Stahl describe superficialmente la vida y usos «típicos» de los asháninka, a su vez que narra, impresionado, las terribles prácticas ligadas a ciertas creencias. Trata de una pareja de esposos quienes, acusados de brujería, fueron asesinados, siendo luego sus tres hijos vendidos como esclavos entre la población mestiza de Loreto (Stahl, 1923a: 32). Para 1924 este misionero afirmaba que las acusaciones de brujería eran la principal causa de muerte entre los nativos del Perené (Stahl, 1924: 14), iniciándose una cruzada a fin de acabar con la influencia ejercida por los chamanes dentro de los grupos asháninka, además del consumo de alcohol y hoja de coca asociado a sus ceremonias religiosas:

«Estos vicios [el alcohol y la coca] los brutaliza al extremo. Ellos están controlados por la superstición. Temen enormemente a la enfermedad, matando a todos los que deliran, creyendo que están poseídos por el demonio. Matan a todos los que tienen enfermedades persistentes (...) las casas de los pacientes de viruela son prendidas con fuego dejando al paciente dentro para quemarse» (Stahl, 1932: 34).

Además, la actividad evangelizadora se convierte en una empresa arriesgada para los propios misioneros que deben involucrarse con gente que vive «bajo el control

26 El adventismo entiende como hechicería la «comunicación y trato con el Diablo (...) capaz de producir fenómenos sobrenaturales» (Alomía, 1996: 189). 
del demonio y la brujería», con la amenaza recurrente de la violencia y la muerte (Stevens, 1925: 9). Otra temprana referencia sobre la enfermedad y la brujería infantil es recogida de la experiencia de Oliver Montgomery, vicepresidente de la Conferencia General de la iglesia adventista y el primer dirigente adventista en contactarse con indígenas amazónicos en el Perú:

«Cuando un miembro de la familia está enfermo, se llama al hechicero y al mismo tiempo comienza sus ceremonias particulares. Él hace una investigación a fondo de la casa, mirando detenidamente en las esquinas, actuando como si tratara de encontrar algo. Mastica hojas de coca y las escupe en la palma de su mano. Presume que la persona enferma ha sido hechizada por algún espíritu. Cuando está finalmente listo para echar la culpa a alguien, siempre elije a algún niño, ya sea en la familia o en alguna otra, y es deber del padre matar a aquel niño» (Burgan, 1923: 11)27.

Dos décadas después, el misionero John Elick anotará la permanencia de la muerte ligada a la superstición en los alrededores de la misión de Nevati, en el Alto Pichis:

«Chaomayo era una niña de 10 años que vivía con su padre y su hermana mayor en la selva. Repentinamente el padre enfermó y, a pesar de lo que el hechicero pudo hacer, al poco tiempo murió. Luego, en armonía con su costumbre, el hechicero comenzó a buscar a la persona responsable de esta muerte (...) Al salir del trance, anunció que Chaomayo había causado la muerte de su padre y por ello, para proteger al resto de la tribu, ella debía ser asesinada. Más adelante su hermana cogió un palo grande del fuego, golpeando cruelmente Chaomayo en la cabeza (...) Después de unos diez días una convulsión muy fuerte se apoderó de ella y falleció, otra víctima de la superstición y la brujería de la selvà (Olson, 1953: 1; el subrayado es nuestro).

Es de entender que estas acusaciones fueron algunos de los comportamientos rituales que más impactan a los misioneros adventistas y que con más ahínco se detallan en las fuentes misionales. La actividad del «witch-doctor» y la muerte relacionada a las acusaciones de brujería, simbolizan no solo la esencia salvaje de la cultura indígena, sino que es la viva manifestación del demonio que, a los ojos de los misioneros, es preciso eliminar por medio de la evangelización, alcanzando la «humanización» de sus usos y costumbres ${ }^{28}$. Otro testimonio de la vitalidad de estas prácticas rituales llega a nosotros a través del relato del maestro Pérez Marcio:

«Cuando en la selva enferma algún indio, sea hombre o mujer, y si después de probar algunos remedios conocidos el mal se llega a agravar, o el

27 Su exposición se complementa con un caso en el que una niña de cuatro años es condenada a muerte y a quien su padre salva, escondiéndola en el bosque, hecho que sin embargo le significa el destierro de su comunidad.

28 «Ahora, en un radio de muchos kilómetros de la misión, estas personas no son más salvajes. Han dejado sus malos hábitos y ya no acusan ni matan más a sus hijos a causa de la brujería, por una firme creencia en el Dios verdadero han superado esta terrible superstición» (Stahl, 1926: 15) 
paciente muere, los familiares lo llevan al curandero o sencillamente lo consultan, haciéndole una exposición del estado del enfermo. El brujo escuchará en silencio o examinará al paciente, en forma muy superficial por cierto, hará ciertas preguntas y después se «reconcentrará〉 hasta saber quién es el causante de la enfermedad o de la muerte de tal persona.

(...) Largas cavilaciones y aspavientos del brujo preceden al momento fatal cuando éste se pone por fin de pie; o sentado en cuclillas (...) extiende su mano sarmentosa y con una voz que pareciera surgir del vientre de la tierra, dice pausadamente: 〈Krite tiene el mal espíritu y debe morir (...) Y debe morir, a pesar de ser inocente, porque el brujo está obligado, porque así es la ley de la selva, a descubrir quién es la persona que entre ellos es el receptor del mal espíritu y que ocasionó una enfermedad o una muerte» (Pérez Marcio, 1953: 165-166)29.

Del mismo modo, hay una continua descripción de las actividades de los shamanes asháninka. En el caso de las fuentes que hacen referencia a la actividad misionera en la década de 1920, incluyen la referencia a importantes corneshas yáneshas, quienes tenían fuerte influencia en los alrededores de la estación misionera de Metraro. En estos años las referencias a los shamanes son continuas y se encuentran contextualizadas en las relaciones antagónicas que representaba la presencia misionera adventista para el dominio ejercido por estos dentro de la sociedad tradicional, minando su influencia a medida que la actividad misionera, sanitaria y educativa se iba extendiendo en la región 30 .

Ferdinand Stahl describió el proceso de formación de un joven shamán y la relación estrecha que existía entre la actividad y el consumo de estimulantes, iniciación que duraba algunos años, hasta que éste se transformaba en un «hombre depravado y brutal», marcado por el uso del masato, jugo de tabaco y la hoja de coca dentro de sus prácticas rituales y sesiones de curación (Stahl, 1932: 34-35).

William Schaeffler describía la performance de un shamán que había iniciado una campaña de desprestigio en contra de la misión de Sutziki, durante una ceremonia que llevó a varios individuos a un estado de trance:

${ }^{29}$ El texto continúa con la descripción del tipo de castigos que le espera al acusado de brujería en caso de la muerte de la víctima «embrujada». Este punto será dramáticamente relatado, entendemos que con el fin de conmover a la feligresía, receptora de las informaciones que los misioneros publicaban en las revistas denominacionales, y principales financistas de la actividad misionera en la Amazonía.

30 Stahl ofrece diversas y detalladas descripciones de la performance del shamán frente a la enfermedad: «Cuando el paciente empeora, el hechicero acusa a alguien en la vecindad de haber embrujado al enfermo. Por lo general, se trata de un niño de seis o siete años, o una viuda sin familia. Los guerreros son enviados inmediatamente a traer a la persona acusada, quien es atada con una cuerda fuerte a un árbol cerca de la casa del enfermo. Se coloca un palo en las manos del acusado y se le ordena a cavar para encontrar lo que está causando el dolor. Si el paciente se recupera, la víctima es liberada, después de haber sido golpeada, pero si el enfermo muere, la víctima es inmediatamente asesinada con palos o estrangulada y el cuerpo tirado en uno de los rápidos ríos» (Stahl, 1932: 34). 
«[el shamán] les dijo [a los nativos] que debían construir una casa de adoración al demonio como la misión adventista tenía para Dios. Así lo hicieron y luego se reunieron para celebrar una fiesta para beber durante dos semanas. Pintaron sus cuerpos, se adornaban con plumas, huesos y plata, chuparon tabaco que se había preparado como jarabe de acuerdo con la costumbre tribal, y tomaron una bebida hecha de diversos tipos de raíces, hierbas y enredaderas, que los llevó a tener visiones. Bailaban, gritaban y cantaban durante días con el acompañamiento de su tom-toms» (Schaeffler, 1931: 3).

El maestro argentino Pérez Marcio ofrece una impactante descripción de la figura del «brujo» entre los indígenas amazónicos:

«(...) es un personaje siniestro y su aspecto causa algo así como una mezcla de miedo y de repugnancia. Y mucho más cuando ha llegado a una edad avanzada, y a los colores chillones con que se pinta y a sus adornos y pelambre hirsuta añade en su rostro y en sus manos el sin fin de canales que forman las arrugas de su piel sarmentosa.

Algunos de estos personajes son a veces menudos, casi insignificantes de cuerpo y tan viejos ya, que dan la impresión de que la muerte los estuviera llamando a gritos. Y sin embargo son ellos los que llaman a la muerte. Pero no para sí, sino para entregarles la vida de centenares de criaturas inocentes» (Pérez Marcio, 1953: 165).

\section{2. Brujería y shamanismo como manifestaciones del demonio}

En una segunda etapa, las fuentes ofrecen otro tipo de explicación a los daños ocasionados por la práctica de la brujería y el shamanismo. En este sentido, a diferencia de los testimonios rescatados de la etapa precedente, los autores encuentran estos fenómenos como plausibles, cuya veracidad respaldan, en algunos casos, por experiencia propia. Es por ello que nos ofrecen posibles explicaciones acerca del «éxito» de estas prácticas, que se manifiestan como fenómenos extrasensoriales. Para fundamentar esta explicación se basan en la propia doctrina adventista, que reconoce a la brujería y hechicería como manifestaciones del demonio, en la eterna lucha antagónica entre el bien y el mal (La Gran Confrontación)31.

Uno de los primeros testimonios adventistas que otorgan una explicación doctrinal a la perseverancia de las prácticas shamánicas dentro de los grupos indígenas amazónicos se rescata del texto de Manuel Pérez Marcio:

31 La doctrina adventista explica que el paganismo (ritos y creencias religiosas practicados por los pueblos indígenas) está relacionado a la actividad del demonio en el mundo y justificado, maniqueamente, dentro de la «Gran Confrontación» existente entre el bien y el mal. Sobre la explicación doctrinal adventista acerca de la lucha entre el Dios judeocristiano y Satanás en el mundo terrenal, véase White (1975). 
«Duele tener que reconocer que la brujería y el espiritismo, que no son más que manifestaciones diabólicas hayan alcanzado un poder tan grande, y que este señorío esté cundiendo y alcance proporciones alarmantes» (Pérez Marcio, 1953: 115)32.

Más adelante, al describir las propiedades extrasensoriales de la ayahuasca que permite, incluso, alcanzar «visiones de hechos acontecidos en el pasado», Pérez Marcio indica que este hecho:

«Nos demuestra el doble efecto de este tóxico: es una droga que ataca el sensorio y produce placeres en detrimento de la salud, y además ayuda a descubrir hechos acaecidos, lo que prueba la intervención directa de los demonios en un fenómeno de semejante naturaleza» (1953: 114).

Sobre el mismo fenómeno, tenemos el testimonio de Ricardo Flores Vidal, quien reporta un caso sucedido en la misión de Nevati, hacia 1963, cuestionándose esta vez sobre los efectos alucinógenos del floripondio:

«Existe una sola respuesta (...) Satanás, tratando de intervenir de mil maneras en la vida de la gente, intentando distraerlos principalmente en la etapa juvenil, les presenta situaciones que explotan la alta dosis de curiosidad que los caracteriza» (Flores Vidal, 2006: 78).

Como explicación a los efectos del alucinógeno, el autor ofrece una respuesta doctrinal: es la manifestación del demonio (Satanás), puesto que:

«(...) los demonios están esparcidos por todo el mundo, intentando hacer pecar a la gente, a fin que sean destituidos de la gloria de Dios» (2006: 78-79).

Más adelante, recoge en Nevati el testimonio de «Dominguillo», quien:

«(...) se alucinaba con ayahuasca con la intención expresa de «ver al diablo〉 quien sin hacerse esperar se le presentaba en forma totalmente clara, de modo que podía ser descrito como un hombre apuesto, amable y con dos pequeños (pero elegantes) cuernecitos en la cabeza» (Flores Vidal, 2006: 78).

En este sentido, la actividad misionera aparece a los ojos de los involucrados como una herramienta fundamental de la divinidad benevolente, quien enfrenta la presencia y predominio del mal entre los hombres del bosque, ofreciendo la esperanza de la salvación para los redimidos:

«Los miembros de las mencionadas estaciones misioneras viven alejados de los errores, y si alguna vez su vida pasada la practicaron, se apartan de ellos porque hay un poder superior al que obra por medio del espiritismo y ese poder es el Dios verdadero» (Flores Vidal, 2006: 78).

32 En otra parte de su texto indica: «En más de una ocasión tuve que escuchar relatos verdaderamente fantásticos, increíbles, pero dichos con una seguridad tal por personas que me merecen la más completa confianza, que al final he tenido que aceptar que realmente suceden cosas terribles, que no son sino manifestaciones de los demonios que han establecido también su reinado de engaños y de miserias en esta inmensa región [amazónica]» (Pérez Marcio,1953: 110). 


\section{3. La muerte de Poñiro}

En esta línea, rescatamos el ilustrativo relato elaborado por el misionero Alejandro Bullón en el que nos narra la muerte del shamán Poñiro. Según narra, Poñiro es atraído por la propuesta cristiana y se asienta en los alrededores de la estación de Metraro, convirtiéndose en uno de los primeros neófitos adventistas del misionado de Ferdinand Stahl (1922-1926):

«Toda su vida creyó estar trabajando para sus dioses; era el sacerdote de sus hermanos, el que oficiaba sus ceremonias religiosas, el que imploraba a los dioses la sanidad para los enfermos aunque para ello tuviese que valerse de ritos sangrientos y grotescos. Sí, toda su vida creyó ser útil a su pueblo (...)» (Bullón, 1999 [1976]: 78).

Sin embargo — continúa el relato—, los camari, espíritus maléficos a los cuales Poñiro había servido, no lo dejarían escapar. A continuación, Bullón recreó una sesión de exorcismo, en la cual el misionero Stahl buscó «arrojar» el demonio del cuerpo de este antiguo shamán. Una noche, un griterío despertó a toda la aldea de Metraro. Era Poñiro quien:

«(...) empezó a desesperarse y gritar porque supo que había ido demasiado lejos y 〈camari〉 no estaba dispuesto a dejarse abandonar» (Bullón, 1999 [1976]: 78).

Frente a esta situación, Stahl se decide a realizar una serie de oraciones y plegarias, acto en el que fue acompañado por todos los nativos que se habían apersonado a la casa de Poñiro.

En medio de la oración —continuó Bullón- «un hachón encendido iluminaba aquel grupo de fieles que, junto al pastor, habían doblado sus rodillas con la esperanza de que el Dios todopoderoso hiciera huir al camari» (1999 [1976]: 79). La sesión terminó trágicamente. Poñiro no pudo resistir «la fuerza del demonio» que vino a cobrar venganza por su «traición» y murió en medio de la noche, entre gritos y alucinaciones. De otro lado, este hecho le sirvió a Bullón para explicar la manera cómo el demonio se manifestaba en el mundo y el peligro que existía para aquel que se atrevía a servirle:

«Stahl aprovechó para enseñarles lo peligroso que resulta entrar en el terreno de Satanás. Les explicó la hechicería, el curanderismo, la brujería no son sino artes diabólicas y quienes ejercen o se someten a estas prácticas se colocan en terreno del diablo y más tarde cuando el individuo quiere limpiar su vida de todo aquello, es reclamado por el señor de las tinieblas como propiedad suya» (Bullón, 1999 [1976]: 78).

Era evidente que el método pastoral usado por los primeros misioneros no escapaba a las comparaciones más directas con la religiosidad tradicional. El hecho de la manifestación del mal y del demonio, presentes en la figura del camari, debió hacerse repetitivo dentro del discurso de los misioneros, aprovechado mediante una performance preparada que les permitiese interiorizar en los nativos su propuesta religiosa. Historias como esta fueron asimiladas por los nativos quienes - como los informantes de Bullón-, continuaron creyendo en la existencia 
de espíritus y fuerzas maléficas, esta vez interpretados dentro del perpetuo enfrentamiento entre el bien y el mal manejado por la doctrina adventista.

\section{LOS SALVADOS DE LA MUERTE33: HISTORIAS DE BRUJERÍA Y REFUGIO MISIONERO}

Desde los primeros testimonios adventistas sobre los asháninka podemos percibir la descripción de acusaciones de brujería y, según los misioneros, de los tormentos a los cuales son sometidos los acusados de ejercerla. Debemos reconocer que hasta la década de 1940 gran parte de los miembros de las comunidades adventistas son niños y jóvenes, «huérfanos» y «fugados» 34 , en muchos casos, acusados de ser los causantes de los padecimientos de otro miembro de su colectividad. Sobre este hecho hay numerosos relatos que describen la llegada de los «acusados» que buscan refugio en las misiones, algunas veces por cuenta propia y en otras entregados por sus padres quienes, impotentes ante la fuerza de las imputaciones, prefieren rescatarlos y entregarlos a la protección de los misioneros. Como indican los testimonios de Ramos Gago (2005: 38), Kuczynski Godard (1939: 27) y Pérez Marcio (1953: 175) son numerosos los niños que residen en las estaciones misioneras, aún cuando estos asentamientos presentan un alto nivel de mortandad prenatal e infantil.

En el caso de los niños acusados de brujería o «huérfanos» dentro de la estación, estos eran entregados al cuidado del misionero quien, en muchos casos, asumía personalmente su cuidado, manteniéndolos «a su servicio» (mission boys). Era de suponer que al carecer de lazos familiares, puesto que se trataba de parias sociales, estos jóvenes asumían con mayor entereza su nueva religiosidad, por lo que, con los años, podían llegar a constituir la base social más confiable para los misioneros. A continuación, presentamos algunos casos de acusados de brujería que se establecían en las misiones y, adicionalmente, un testimonio sobre la respuesta de los asháninka conversos frente a la «presencia del demonio» dentro de una comunidad en el Pichis.

\section{1. «Jaime Salvado de la muerte»}

El misionero Próspero Ramos Gago (2005: 40-43) describió las historias de un niño y un joven, ambos acusados de brujería, quienes llegaron a la estación de

33 Referencia a los niños y jóvenes asháninka acusados de hechicería que se refugian dentro de las estaciones misioneras adventistas (Pérez Marcio, 1953: 175).

34 Debemos entender que la categoría huérfano para los grupos amazónicos no indica, necesariamente, la carencia de ambos progenitores, sino que responde a razones de índole sociocultural, por lo cual son desconocidos como parte del grupo familiar, convirtiéndose en extraños, en parias sociales. Los «fugados» son aquellos individuos que, acusados de brujería, escapan de sus comunidades para evitar la ejecución de las prácticas punitivas, como también aquellos que huyen de los traficantes de esclavos indígenas o patrones mestizos locales y se «refugian» en las estaciones misioneras. 
Metraro, buscando refugio frente a la amenaza de muerte recibida en su grupo al ser acusados de brujería. Estos hechos se habrían suscitado hacia 1926, año en el cual Ramos se desempeñó como maestro en la escuela de la misión.

En el primer caso se trataba de un yerno del jefe Zárate, al cual hemos hecho referencia anteriormente, quien huyó ante la amenaza de muerte que recibió una vez que Zárate, al enfermar, lo señaló como el causante de su padecimiento:

«Cierto día trabajando con los alumnos en el campo de cultivo, un joven campa (...) vino corriendo hacia mí, el joven estaba llorando, me pidió que lo protegiera porque Zárate lo buscaba para matarlo; había sido amarrado de los brazos por Zárate; me mostró las marcas del jebe en sus brazos; me contó que hizo un esfuerzo supremo para defenderse y logró escaparse. Este joven (...) vivía en la casa de Zárate; el curaca creía que el joven era brujo y le había hecho un maleficio; por eso se encontraba enfermo. El único modo de sanarse era matando al joven. Aceptamos al joven en la Misión, se quitó la túnica campa, le dimos camisa y pantalón; se unió a los trabajadores de la Misión, fue salvado de la muerte» (Ramos Gago, 2005: 40-41; el subrayado es nuestro).

El segundo caso relataba la historia de Jaime, un niño de cuatro años que fue entregado por su madre al misionero, también al ser acusado de brujería:

«Cierto día una madre campa muy agitada vino a la Misión acompañada de otras mujeres campas; trajo a su hijito de cuatro años y nos dijo que venía para salvar la vida del niño; el padre estaba enfermo; el hombre imaginó que el niño era brujo; que lo había embrujado; y ése era el motivo de su enfermedad; el padre pensó que el único modo de sanarse era matando al niño. La madre campa informada del trabajo de bien que hacían los misioneros trajo a su niño a la Misión; después de dejar al niño regresó a su lugar, aceptamos al niño y lo cuidamos. Muchos casos similares sucedieron en Metraro. La Misión era un verdadero lugar de refugio, curación y salvación» (Ramos Gago, 2005: 43).

\section{2. El caso de Chave Mariano}

Dentro de los relatos que describen el refugio de niños acusados de brujería al interior de las estaciones misioneras cabía destacar la historia de Chave, la pequeña niña asháninka de diez años, hija del jefe Mariano, quien, según las fuentes misioneras, hacia 1923 fue entregada a Ferdinand Stahl por su propio padre debido a que la pequeña ha sido condenada a muerte en dos ocasiones acusada de hechicería. Aún cuando su padre era un importante líder, no podía defender a su hija, puesto que el shamán ya la había acusado en dos ocasiones de ser la causante de la enfermedad de algunos miembros del grupo. Stahl relataría este hecho en un simposio misionero, hacia mayo de 1926, siendo resumido de la siguiente manera por una cronista del evento: 
«Hace dos años su padre, un jefe de Campa, llegó a la estación acompañado de unos cien hombres. Durante varios días fueron entretenidos como visitantes, a continuación, el jefe le dijo al pastor Stahl, «Mi hija estará a salvo con usted. Ha sido condenada dos veces a muerte y no puedo rescatarla una tercera vez. Deseo traérselà. Desde entonces Chave Mariano ha estado con ellos en su casa» (Clement, 1926: 6).

Una vez instalada en Metraro, quedó al cuidado de los misioneros, viviendo en su propia casa y participando del primer grupo de estudiantes de la escuela misionera. Esta niña, con una capacidad intelectual superlativa, aprendió rápidamente a leer, escribir e incluso a entonar himnos adventistas en inglés (Guthie, 1925: 9). Bautizada como Elena (Hellen) Stahl, fue adoptada por los misioneros quienes, la llevaron consigo a una gira misionera que incluyó la Conferencia General (reunión institucional mundial adventista) en los Estados Unidos y Europa. Se dice que en una sesión de la Conferencia General de 1926, Chave fue invitada a cantar ante la audiencia y su presentación fue tan emotiva que mantuvo la atención de las principales autoridades de la Iglesia durante todo el tiempo que restaba del evento.

Desde 1927 acompañaría a los Stahl durante el tiempo que estuvieron en actividad misionera en lquitos, dirigiendo la Misión del Alto Amazonas y formándose como maestra misionera entre los grupos étnicos de la zona. Más adelante se graduaría como enfermera en la Clínica Adventista de Chulumani, en Bolivia, hacia 1944.

\section{3. La historia de Oijani}

Pérez Marcio (1953: 168-175) recogió la historia de Oijani, una niña asháninka de siete años que fue rescatada por su madre ante una acusación de brujería, llevándola hasta la misión de Sutziki. El autor afirmó haber visitado la estación de Sutziki en el tiempo en que el misionero Jens Ruskjer se encontraba dirigiéndola (1935-1944). Al parecer, sería este misionero quien le narró la historia de Oijane como un típico caso de niño refugiado en la estación (que para esta fecha eran muy numerosos). En las Actas de la Misión Peruana35, encontramos un interesante documento que nos permitió ubicar históricamente este caso. El nombre Ojanie apareció en una lista de bautizados del 3 de octubre de 1936. Este dato nos permitió ubicar el hecho del «refugio» de la niña en Sutziki hacia 1934 ó 193536. Pérez Marcio concluyó la historia de Oijani indicando su asentamiento definitivo en Sutziki, donde, luego de unos años, contraería matrimonio con un joven indígena, también neófito de la misma misión.

\footnotetext{
35 Órgano máximo dentro de la institucionalidad adventista en el Perú hasta la década de 1960. Sobre los cambios dentro de la división territorial adventista, con especial énfasis en la Amazonía peruana, véase La Serna Salcedo (2009).

36 «Lista de bautizados en Sutziki», Actas de la Misión Peruana, Libro I, Acuerdo 1531, 8 de octubre de 1936. Estamos seguros que se trata de la misma persona. La diferencia gramatical (Oijani para Pérez Marcio y Ojanie para Ruskjer) es un hecho recurrente al referirse a nombres propios en las fuentes escritas adventistas.
} 


\section{4. Rescatado por Daniel Asín}

Otro caso fue descrito por el pastor Alejandro Bullón, quien informó sobre una acusación de brujería ocurrida, hacia 1965, en la comunidad de Incariaro en el Perené medio. Es la historia de un niño asháninka, rescatado por el misionero Daniel Asín luego que fuese acusado de brujería y «seguramente condenado a muerte». Esta comunidad, si bien tenía miembros activos adventistas, incluía a varias familias renuentes a integrarse al adventismo. Es por ello que, según indica Bullón, aprovechando el misionero un descuido de sus captores, rescató al niño y se lo llevó consigo hasta el poblado colono de Pampa Silva, donde tenía su casa37. Al tiempo, este muchacho fue trasladado a Lima y formado dentro de los centros de educación adventista. Actualmente se encuentra en Brasil y hasta hace poco participaba dentro de la organización eclesial.

\section{5. El demonio llega a San Pablo}

Dentro del interesente texto elaborado por el maestro adventista Ricardo Flores Vidal, bajo el sugerente título Fue dicho: de este fruto no comerás (Flores Vidal, 2006)38, encontramos un par de relatos referidos a la presencia de «manifestaciones demoníacas» entre los creyentes adventistas de la Amazonía peruana. El trabajo del autor responde a una intencionalidad pastoral cristiana, alarmando a la feligresía sobre «la tentación del pecado en el mundo actual», que se manifiesta en el consumo de ciertos alimentos exóticos, bebidas alcohólicas, la sexualidad prematrimonial, comportamientos «indecorosos» (homosexualidad, desnudez, bailes, embriaguez) prohibidos todos por la doctrina adventista, pero evidentemente vigentes dentro de la cotidianidad vivencial de los pobladores amazónicos. Por el propio interés pastoral que tiene el autor, ofrece amplias descripciones de situaciones en que se manifiestan estos fenómenos, inaceptables y peligrosos para el mantenimiento de una comunidad religiosa adventista 39.

Los relatos describen acusaciones de brujería y «visiones» por consumo de psicotrópicos en las comunidades adventistas de Nevati y San Pablo, en el Alto Pichis. Según afirma el autor, se hace referencia a acontecimientos reales, de los cuales fue un observador privilegiado. Son dos relatos extensos que ocupan casi

37 Alejandro Bullón Paucar. Entrevista personal, 20 de julio de 2004.

38 El título hace referencia a la primera norma de comportamiento proscriptiva dentro de la Biblia, según la cual Dios prohibió a la pareja primigenia comer del árbol de la sabiduría (Génesis).

39 «El objetivo de este libro (...) es presentar la preocupación del autor por sus habitantes frente a los abusos que viene cometiendo el archiengañador y padre de la mentira [representado por el demonio judeocristiano], con las humildes, sencillas y crédulas familias de nuestra selva, y lo que más coraje da, es que su blanco sean los jóvenes cristianos, tratando de minimizar la noble y sacrificada labor de los misioneros gringos y no gringos, que superando las dificultades que representa vivir y moverse en la espesura forestal; se han propuesto predicar las buenas nuevas de salvación a los nativos, tratando de trocar sus salvajes costumbres con mejores formas de vida, mientras esperamos todos el anunciado segundo advenimiento del señor Jesús a esta tierra» (Flores Vidal, 2006: 131) 
la mitad de su texto, los que nos permiten observar la manera en que los grupos asháninka convertidos al adventismo entienden este tipo de fenómenos y la manera en que los enfrentan, valiéndose tanto de elementos religiosos adventistas, como de expresiones de la religiosidad tradicional amazónica.

Según va trascurriendo el relato, el autor anota que, hacia 1963, llegó a la zona del Pichis como mercachifle. Para esta fecha, ambas agrupaciones tenían alrededor de diez años de establecidas, conformadas en gran parte por asháninka y algunos yánesha originarios del Perené (específicamente de la misión de Sutziki), quienes, hacia 1948, se trasladaron rumbo a esta región por iniciativa de los misioneros adventistas 40 .

Empieza describiendo el consumo de té de toé (floripondio), práctica recurrente en un grupo de jóvenes de la comunidad de Nevati en sus horas de ocio.

«(...) narran que mientras se encuentran bajo los efectos psicoactivos de dicha sustancia, ellos pueden ver cosas muy hermosas, paisajes desconocidos, ciudades, colores y brillos exóticos, oír música y muchos otros deleites que en la vida real pudieran desear mas no obtenerlos. Afirman que podían conocer lugares y cosas que en la realidad, saben que existen en otros sitios, pero que ellos no pueden llegar a conocer de otra manera, así como hombres y mujeres muy bonitos. Bajo estos efectos los seres inanimados cobran vida y los animales y plantas se personifican y pueden comunicarse con ellos» (Flores Vidal, 2006: 77-78).

Flores Vidal afirmaba que todos los pobladores de Nevati, incluso las autoridades de la Iglesia Adventista, tenían conocimiento de este hecho41. Más aún, al ser la sede central del Distrito Misionero, el propio pastor norteamericano, Dwigth Taylor, instalado en la comunidad, tenía conocimiento de ello.

Más detallado aparece el relato sobre la presencia del demonio en la comunidad de San Pablo. En esta ocasión, Flores Vidal describe la presencia de una serie de acontecimientos extraños que se inician con la llegada a Nevati de una mujer de nombre Shivániqui, quien, huyendo de un grupo de hombres que la quieren asesinar, acusándola de «bruja», busca refugio en la comunidad. Una vez aceptada en la misión, los dirigentes de la Iglesia comienzan a preguntarle los motivos por los cuales es acusada por este grupo de hombres, entre los que se encuentra su propio esposo, de ser una bruja. Ante ello, la mujer responde que, tras consumir un fruto extraño del bosque «(...) comencé a ver gente extraña, diferente, desconocida de estatura mediana, y además todos estaban desnudos (...) Al principio estaban un poco tímidos, no me hablaban, pero después, en otras noches ya querían hablarme porque iban entrando en confianza» (Flores Vidal, 2006: 98). Mientras Shivániqui continúa haciendo una serie de descripciones de estas alucinaciones, reconoce a una mujer dentro de la comunidad de nombre

40 Sobre la migración de los neófitos adventistas asháninka del Perené hacia el Pichis, véase La Serna Salcedo (2004: 272-273).

${ }^{41} «(\ldots)$ hombres, mujeres y hasta niños lo comentaban aunque no en forma abierta sino como si se tratara de personas en estado agónico y a punto de morir» (Flores Vidal, 2006: 79). 
Pachori, bautizada por los misioneros como Bernardina, quien, a impresión del autor, es «una mujer piadosa, cristiana y devota», colaboradora con las actividades de la Iglesia y solidaria con los demás miembros de la comunidad.

Bernardina es acusada por Shivániqui de participar en sesiones de hechicería. Negando los cargos se recluye y desaparece del relato del autor (al parecer, en estos días tensos, se retira a una comunidad vecina). Sin embargo, al ser reconocida como «bruja» por toda la comunidad, Bernardina no podrá escapar de acusaciones posteriores. Daniel, conocido como «Puño» —otro poblador de Nevati-, la confrontará acusándola de ser la causante de un dolor recurrente que le afecta el pecho. Según afirma Flores Vidal, al enfrentar Daniel a esta mujer, hasta el punto de amenazarla con destruir su casa, obtiene de ésta la confirmación del daño. Bernardina asume su responsabilidad, reconociendo que le ha puesto una espina en su pecho y se compromete a revertir el hechizo.

Más adelante, Shivániqui señala a un grupo de muchachos a los que afirma haber conocido en sueños. Estas acusaciones originan que la directiva de la Iglesia local iniciara una serie de interrogaciones sobre estos acusados, llegando a descubrir a un grupo de 14 jóvenes asháninka, entre varones y mujeres, quienes han consumido «frutos raros» que han provocado en ellos «visiones y comportamientos anormales». Según el testimonio de Hortencia (13 años), quien afirma haber recibido de un compañero de la escuela un pedazo de papaya «[que] parecía le habían echado malaria42〉. Al consumir la fruta empiezan sus visiones de seres extraños quienes entran en contacto con ella, e incluso le proponen tener contactos sexuales. Con todos los testimonios recogidos ese día, Flores Vidal tiene la oportunidad de elaborar un cuadro «sintomatológico» de los efectos del consumo de estos productos (Flores Vidal, 2006: 108).

\section{REFLEXIONES ACERCA DE LA HIBRIDEZ RELIGIOSA ADVENTISTA EN LA AMAZONÍA}

El acercamiento de muchos grupos familiares asháninka a la propuesta religiosa adventista a lo largo del siglo XX se debe —además del ofrecimiento de una serie de bienes y servicios apreciados por los indígenas - al hecho de que los misioneros han sabido ofrecer las herramientas necesarias para hacer entendible, dentro de los patrones culturales tradicionales, los cambios alrededor del universo indígena. Esos cambios son en gran medida negativos y socialmente destructivos, como nuevas y devastadoras enfermedades, la intensiva colonización o el estado de marginación frente a los colonos e intermediarios foráneos (Narby, 1989). La propuesta religiosa expuesta por los misioneros de manera clara y sencilla ha sido entonces asumida por los asháninka sin romper con sus patrones cosmológicos tradicionales. Como sabemos por las fuentes, los misioneros no han tenido ningún problema en convivir, inicialmente, con las prácticas «demoníacas o pecaminosas» que manifiesta la cultura

42 Se refiere al olor que emana del aldrín, insecticida usado por el Programa de Erradicación de la Malaria. 
tradicional asháninka. Podemos notar una actitud ambigua entre permisividad/ represión de los valores y costumbres indígenas. El contacto inicial, por supuesto, excluye todo tipo de referencia a aspectos espinosos como el consumo de animales y bebidas impuras, el descanso sabático o la poligamia. A medida que el misionero observa la penetración y «asimilación» del programa misional en los nativos es que empiezan a hacerse restrictivos en relación a estos aspectos.

El adventismo entiende que la presencia del mal es explícita y se manifiesta constantemente en la vida de los hombres ${ }^{43}$. Así, los misioneros buscan dar una explicación a los fenómenos extrasensoriales desde su perspectiva doctrinal, enfrentando las acusaciones de brujería que conllevan a la muerte o el suplicio del acusado. En el caso de alguna «manifestación diabólica», doctrinalmente se espera que la aplicación de medidas psicoterapéuticas (oraciones) acabe con el padecimiento. Esto es lo que observamos en el caso del exorcismo colectivo ejecutado en Nevati, descrito por Flores Vidal. Esta práctica no es ajena a la experiencia indígena que asume la existencia de seres maléficos que habitan alrededor del mundo, los cuales, bajo ciertas circunstancias extraordinarias, pueden «atraer» hacia sí a algunos individuos de la propia colectividad. Ante ello, el ayuno se enmarca bajo el sentido de purificación ritual. No solo eso. Si seguimos analizando este caso, podemos ver que la inculpación/confesión descrita en los jóvenes de Nevati tiene mucha analogía con el relato bíblico del origen del pecado, según el cual el demonio, bajo la forma de una serpiente, ofrece un fruto prohibido del árbol del conocimiento a Eva la cual, a su vez, lo ofrece a Adán. Es posible que la constante referencia al pecado en la actividad pastoral de los misioneros, mediante el uso de este relato bíblico, haya generado, en este caso, una autoinculpación colectiva.

Posteriormente, el relato describe una «purga colectiva», en la cual los catorce «infectados» son tratados por Pedro Acco, diácono de la iglesia de Nevati, y mediante el consumo de plantas medicinales realiza una «limpieza» (dieta) para «sacar al demonio» de los cuerpos de los jóvenes. Lo interesante es que toda la comunidad participa de este acontecimiento, acompañando este ritual con cánticos religiosos adventistas. Incluso se describe la participación del maestro mestizo, Félix Parco. Según concluye el autor, luego de este rito de purificación, ayuno y encierro por un lapso de nueve días —en los que aún se presentan las «visiones demoníacas»—, el tratamiento concluye con la mejoría y curación de los jóvenes (Flores Vidal, 2006: 109-119).

Este hecho nos lleva a plantear la existencia de espacios de hibridez en las prácticas religiosas vigentes al interior de las comunidades adventistas ${ }^{44}$. La información

${ }^{43}$ Entre los creyentes adventistas se utiliza la frase «se ha entregado al mundo» para referirse al alejamiento de un miembro de las actividades de la Iglesia. En este sentido, el grupo de creyentes se presenta como un espacio sagrado, separado del mundo terrenal que, hasta cierto punto, está dominado por las fuerzas del demonio.

44 Sin necesidad de entrar en el debate acerca del sentido de la conversión religiosa asháninka, hablamos de hibridación basándonos en la propuesta de Santos para quien, en el caso de los cambios dentro de los patrones culturales yánesha, la hibridez se entiende como una permanente 
que se posee defiende la existencia de manifestaciones rituales fusionadas dentro del comportamiento religioso asháninka, donde coexisten expresiones rituales «tradicionales» y católicas anteriores, de manera más o menos evidente, sin que ello signifique un desligamiento del colectivo religioso con el cual el individuo se siente identificado; es decir, con el adventismo. Sobre ello ya habíamos generado una primera reflexión para el caso de los líderes políticos asháninka, quienes deben compatibilizar las creencias y normas proscriptivas adventistas con la propuesta reivindicativa, cultural y social de su pueblo. Esa se manifiesta en el rescate de la tradición, muchas veces representada por el baile, la música, bebidas y productos estimulantes y la comida en base a carne de animal de monte, prohibidos en la mayoría de los casos por la doctrina adventista45.

Observamos que las creencias y prácticas culturales tradicionales han mantenido vigencia dentro de los grupos conversos al adventismo e integrados en las misiones. Si bien muchas veces pasa inadvertido, esta situación se hace evidente en momentos de crisis, sobre todo frente a la amenaza de la muerte y la violencia producto de la opresión externa, y la enfermedad. Sin embargo, la mayoría de las veces la incapacidad de los misioneros de percibir este hecho origina una fuerte presión cultural sobre los asháninka, quienes deben asumir, aleatoriamente, diversa influencia cultural foránea y rechazar la cultura propia, constantemente desprestigiada por el propio discurso religioso adventista. Ya en la década de 1960, el misionero Elick reconoce esta contradicción, indicando que la falta de visión de los misioneros cristianos, por lo general desinteresados en comprender la complejidad de la cosmovisión asháninka, es lo que impulsa a los nativos al rechazo de la penetración cultural y, a la larga, induce al retroceso de la propia labor evangélica46.

Es imposible que el adventismo haya podido ser asumido por los asháninka sin haber entrado en un lento proceso de asimilación lo que, a la larga, permitiría la «aceptación» de gran parte de sus doctrinas y normas proscriptivas. Sobre ello los testimonios indican la reaparición de prácticas rituales y «costumbres ancestrales»

práctica de aculturación «(...) como el resultado de un choque de tradiciones y como expresión de una duradera apertura de los yáneshas hacia los otros» (Santos, 2009: 492). En tal sentido, asumimos que las prácticas y doctrinas adventistas han de ser incorporadas dentro del sistema cosmológico asháninka en la medida que ofrezcan respuestas a los nuevos desafíos abiertos en un mundo en constante transformación. Como afirma Gow para el caso del uso y significado de la ropa entre los indígenas amazónicos, entonces, la aculturación no debe entenderse como el proceso de «apropiación» de la cultura de los foráneos, sino como un proceso dinámico $-\mathrm{y}$, evidentemente, de larga vigencia entre las sociedades amazónicas en su relación con diversos pueblos y no ligado de manera exclusiva a procesos modernos-, como la manifestación del deseo por obtener ciertos objetos y conocimientos a partir de la creación de nuevas relaciones sociales (Gow, 2007: 283-304).

45 Es el caso de los dirigentes políticos formados dentro de espacios de socialización adventistas, quienes, en las últimas décadas, han asumido las prácticas tradicionales como forma de recuperación del bagaje cultural del pueblo asháninka (La Serna Salcedo, 2009).

46 «(...) los misioneros, con muy pocas excepciones, no perciben la importancia de la cosmovisión campa en el mantenimiento de su modo tradicional de vida. Los campa aceptaron entusiastamente los artefactos y las formas occidentales hasta cierto punto, luego rechazaron - a menudo con violencia - los rasgos extranjeros y regresaron a sus viejos tiempos» (Elick, 1969: 235). 
en situaciones especiales de crisis, tanto en el plano comunitario — como los descritos por Flores Vidal en Nevati y San Pablo_-, así como en el plano personal. El misionero Siegfried Neuendorff, por ejemplo, describe el hecho de que en Unini la gente vuelve a sus prácticas tradicionales cuando hay una amenaza real de muerte sobre ellos:

«(...) en momentos de crisis la gente volvía a sus costumbres paganas pintándose la cara o golpeando detrás de la cabeza al pariente que agonizaba» (Neuendorff, 2005: 120).

Del mismo modo, pero con una perspectiva distinta acerca del valor de la cultura asháninka, John Elick — director de la estación de Nevati entre 1951 y 1955-, reconoce la permanencia de una serie de ritos y prácticas tradicionales al interior de la población asentada en Nevati y San Pablo, como por ejemplo, las reglas proscriptivas a la actividad del padre durante el embarazo (Elick, 1969: 177) y los métodos anticonceptivos por medio del uso de plantas «semisecretas» (1969: 174). Un caso que le genera especial atención es la curación por medio de baños de vapor. Elick afirma haber observado la aplicación de esta técnica de curación muchas veces, incluso en la propia misión de Nevati, puesto que los neófitos «no ven inconsistencia entre esta práctica y el cristianismo ya que ninguna manipulación de los espíritus está involucrada» (Nevati, 1969: 220). Quien Ileva a la práctica esta clase de curaciones es un tipo específico de shamán, el cual se diferencia del típico sheripiari, por abstenerse del uso de fitotrópicos y estimulantes. Relata el interesante caso de Patsenti, un joven maestro de las escuelas misionales del Pichis, quien a pesar de haber pasado gran parte de su vida en estrecha relación con la misión, es un reconocido satantinkari (quien cura con baños de vapor) 47.

El mundo religioso asháninka es dualista, con elementos contrapuestos y, a su vez, complementarios. Desde la tradición amazónica este modelo cosmológico se repite constantemente. Como lo resumen Brown \& Fernández:

«(...) el universo espiritual de los asháninka es notablemente dualista, casi maniqueo. Los espíritus son benévolos o demoníacos. Los espíritus benévolos (tasorentsi o amachénga) poseen poderes especiales sobre los elementos, las plantas y los animales y sobre la vida misma. Por encima de todos está el Sol (Pavá, Tasorentsi o a veces dios). Pavá es el Padre, el creador, el que vela sobre todo. Luna (Kashíri) es una figura ambivalente, el donador de la agricultura, pero también una ávida figura que engulle a los muertos. Sol, Luna y otros seres poderosos pueden enviar espíritus para ayudar a los ashaninka. Los demonios (kámari), por otro lado, aparecen bajo infinidad de formas para confundir y matar. Siempre hay que estar alertas a sus subterfugios» (Brown \& Fernández, 2001: 12).

La doctrina adventista plantea un modelo cosmológico similar. Según Hellen G. de White en El Gran conflicto — texto fundamental para entender la teología adventista - el tiempo en que vivimos está marcado por la lucha eterna de dos

47 «Al preguntarle el autor sobre el origen de este don para curar, Patsenti respondió que Pava (Dios) otorga este poder a algunas personas» (Elick, 1969: 219-220). 
poderes ambivalentes, el bien y el mal, enfrentamiento que se evidencia en el mundo real y es perceptible de muchas maneras: el bien, por medio de Jesucristo y su poder benefactor, los ángeles y los dones, mientras que el mal, por la intervención del demonio en la vida de los seres humanos a través del pecado que genera la destrucción, el dolor y la miseria-. Frente a este estado de anomia social, el mensaje adventista ofrece a los hombres la esperanza en la resurrección.

Otro aspecto a tomar en cuenta, en relación a la equivalencia entre la religiosidad asháninka y la cosmovisión adventista es el estado del mundo actual en el que habitan los hombres. ¿Por qué existen las enfermedades, miserias y la marginación de los asháninka? La visión tradicional indígena sostiene que es porque se ha quebrado el puente que existe entre el mundo de los hombres y el mundo espiritual, roto ante la irrupción de las fuerzas infraterrenales en el mundo idílico, que traen el mal, la enfermedad y la desdicha (Elick, 1969). De manera similar, para el adventismo - dentro de su concepción escatológica- vivimos la etapa final del mundo, antesala a la segunda venida de Cristo a la Tierra. La parusía es inminente y solo queda a los hombres estar «preparados». Frente a ello, se manifiestan los «signos de los tiempos» finales (guerras, epidemias, hambre, contaminación), situaciones que nacen del origen mismo del mal: el pecado. La esperanza descansa en el retorno del Mesías, una vez que acontezca el juicio final y el mundo sea purificado, con la destrucción del mal y el nuevo reinado de Cristo en la Tierra.

Para acercarnos a la interpretación de la cosmovisión indígena bajo la influencia del discurso adventista hemos recogido el testimonio de Enrique Casanto, intelectual asháninka y creyente adventista de tercera generación. Casanto reconoce un cambio del concepto de la divinidad. Aparece el término Pava Peroni, «dios verdadero», que se viene a superponer a las divinidades anteriores, que aparecen sujetas a éste. A continuación, nos ofrece un relato personal que ejemplifica este proceso de hibridación religiosa, una vez que los conceptos cristianos fueron incorporados en el esquema cosmológico tradicional:

«Un asháninka joven ya no tiene esta visión [del universo asháninka dividido en tres espacios]. Dicen nosotros venimos de Pava Peroni. Pero este Pava Peroni nace cuando ya está evangelizado, mientras para ellos el dios, con minúsculas es considerado el sol, la luna. Hasta el año 1966 todavía existía la mamá de mi abuelito, ella decía nosotros antes adorábamos el sol, la luna, la tierra, la candela. Yo le preguntaba, era muchacho todavía, abuelita, ¿por qué adoramos al sol? Porque nos alumbre, me decía. Adoramos a la luna porque ha sido mujer y porque produce las plantas, algodón, yuca, pituca. [Casanto continúa] ¿Y ahora, por qué hacemos culto [celebración religiosa adventista]? Ah, porque ahora ya ese dios que antes adorábamos ya no es un dios verdadero, sino es un dios como quien dice en segunda etapa. Así aparece esta palabra Pava Peroni, pero antes no, consideraban dios al sol y la luna. Cuándo cambia esto, con la llegada de los adventistas, cuando empezamos a adorar a un dios verdadero y no a uno falso» 48 . 
Desde la visión de los maestros, dirigentes y antiguos misioneros asháninka como es el caso de Casanto-, existe una clara división ontológica entre dios (con minúscula), con el que se hace referencia a las divinidades benevolentes tradicionales, y el «Dios verdadero», encarnado en la figura del dios cristiano, inculcado por el adventismo ${ }^{49}$. En la vida cotidiana este Dios verdadero se enfrenta al demonio [y los dioses falsos] quienes buscan atraer a los asháninka hacia el pecado, condenándolos a la muerte eterna. Esta apreciación nos indica la manera en que los distintos misioneros han explicado - a oídos de los neófitos nativos y cómo luego estos procesaron dicha explicación doctrinal-, las manifestaciones extraordinarias que acontecen a su alrededor y que, tradicionalmente, han sido imputadas a los espíritus malévolos.

\section{A MANERA DE CONCLUSIÓN: LA HECHICERÍA EN LA ACTUALIDAD}

«La brujería existe porque el diablo existe. Pero el diablo es un enemigo vencido. Para el que cree en Dios la brujería no entra a su casa»50.

Diversas conversaciones entabladas con líderes asháninka de formación adventista incidieron en nuestra apreciación acerca de la necesidad de hacer un repaso sobre la ocurrencia de estas prácticas rituales desde la perspectiva misionera. Anotamos en estos dirigentes, sobre todo en la región del Pichis, la preocupación por la permanencia de la «brujería» dentro de las agrupaciones asháninka, situación que, conjuntamente a los «chismes» y el «individualismo», apareció como uno de los principales problemas que debilitaban internamente a las comunidades nativas51.

Según el testimonio de Misael Mendoza Ucayalis2, ex presidente de la ANAP, la organización política asháninka del Pichis y dirigente de la hoy llamada «Asociación de Parcelarios de Nevati»53, la persistencia de estas acusaciones dentro de las comunidades nativas era algo evidente. Contaba que durante el período que presidió la organización, a inicios de esta década, varios casos de este tipo llegaron hasta sus manos a fin de ser solucionados. En alguna ocasión las acusaciones Ilevaron al asesinato de uno de los imputados de ser el causante del «daño»y los responsables del hecho, familiares del supuesto agraviado, fueron entregados a la justicia del Estado. No obstante, por propia disposición de la organización indígena de intermediar en este caso de diversidad cultural,

49 Es importante recordar el sentido de obra salvífica que encierra la actividad misionera para el adventismo. Los relatos recogen una visión que expresa la dicotomía entre el salvajismooscurantismo-dioses paganos frente al cristianismo-civilización-Dios verdadero. Bajo esta lógica, el adventismo mantiene institucionalmente su propuesta de «evangelización contextualizada» como efectivo agente modernizador entre las diversas poblaciones indígenas.

50 Marcos Cruz Santos. Entrevista personal, 18 de julio de 2005.

51 Marcos Cruz Santos. Entrevista personal, 18 de julio de 2005.

52 Misael Mendoza Ucayali. Entrevista personal, 20 de julio de 2005.

53 Antigua estación misionera de Nevati. 
los implicados pudieron ser liberados al poco tiempo. En otro momento, nos detalló su intervención en el caso de un comunero que, acusado de los mismos cargos, fue amenazado de muerte. A fin de evitar que el conflicto llegara a mayores, Mendoza tuvo que ejercer su autoridad, «liberando» al acusado de la casa en la que estaba apresado. Empero, éste fue posteriormente expulsado de la comunidad y era uno de los muchos parias que vivían en los alrededores de Puerto Bermúdez.

Sin embargo, el caso más significativo que nos describió este dirigente fue el de una mujer, también acusada de brujería, que fue traída por la familia del afectado ante su persona a fin de ejercer justicia. La mujer, quien confirmaba el «daño» cometido, fue llevada por la autoridad política indígena ante el fogón de la familia a fin de «recoger los restos de comida con los que había realizado el embrujo». Al igual que en el caso anterior, luego de ser sometida a un castigo físico y psicológico, la mujer fue liberada, obligándole no obstante a abandonar su casa y establecerse en otra comunidad.

Durante nuestra visita a la comunidad nativa de Miritiriani, en el Azupizú, el maestro adventista Manuel Rojas, indagado sobre este asunto, nos indicó la persistencia de estas acusaciones dentro del centro poblado. Detalló el caso de una mujer, casada y que vive muy cerca del centro del asentamiento — donde antes se encontraba la pista de aterrizaje-, quien era considerada una «bruja» por los pobladores, condición que significó su separación de las actividades del resto de la comunidad 54 .

Hacia 1984 Rojas Zolezzi anotó, durante su trabajo de campo, el caso de un asesinato ligado a una acusación de «brujería» en la comunidad de Río Jordán (antigua misión adventista) en el río Neguachi. Según refirió, un brote de sarampión afectó ese año a la comunidad, lo que originó la muerte de una niña por esta infección y la desaparición de otra, acusada de ser la causante del «daño». En un contexto tan complejo como éste, donde las «relaciones entre la tradición y la modernidad» se hicieron particularmente evidentes, fue la autoridad local —en este caso el Juez de Paz-, quien tuvo que intervenir asumiendo, según afirma Rojas Zolezzi, una posición muy similar a la de Misael Mendoza, como intermediario y apaciguador, evitando una mayor confrontación entre las familias involucradas (Rojas Zolezzi, 1994: 264-265).

Lo anteriormente expuesto nos indica que los adventistas asháninka mantienen la creencia en la manifestación palpable de los seres demoníacos en el mundo. Sin embargo, sobre su creencia «tradicional», que sindica la enfermedad y el daño a fuerzas maléficas del inframundo _Elick (1969); Santos (2005)_, ellos han asociado la interpretación adventista, que lo entiende como manifestaciones de Satanás, el demonio judeocristiano y «eterno enemigo de la humanidad», que se hace presente en el mundo y busca alejar a los hombres del estado de santidad que deviene de su entrega a la Iglesia; más aún cuando el «final de los tiempos» (parusía

\footnotetext{
54 Javier Pascual Rojas. Entrevista personal, 15 de julio de 2005.
} 
cristiana) es un hecho inminente55. Esta orientación condiciona la respuesta de los líderes nativos, quienes justifican un tipo de accionar frente a estos fenómenos recurrentes, respuesta que debe corresponder al contexto y al grado de integración que tiene su sociedad con respecto a la sociedad nacional, pero generando una explicación inherente a la cosmovisión asháninka que pueda satisfacer a los implicados, independientemente al hecho de ser estos cristianos o no.

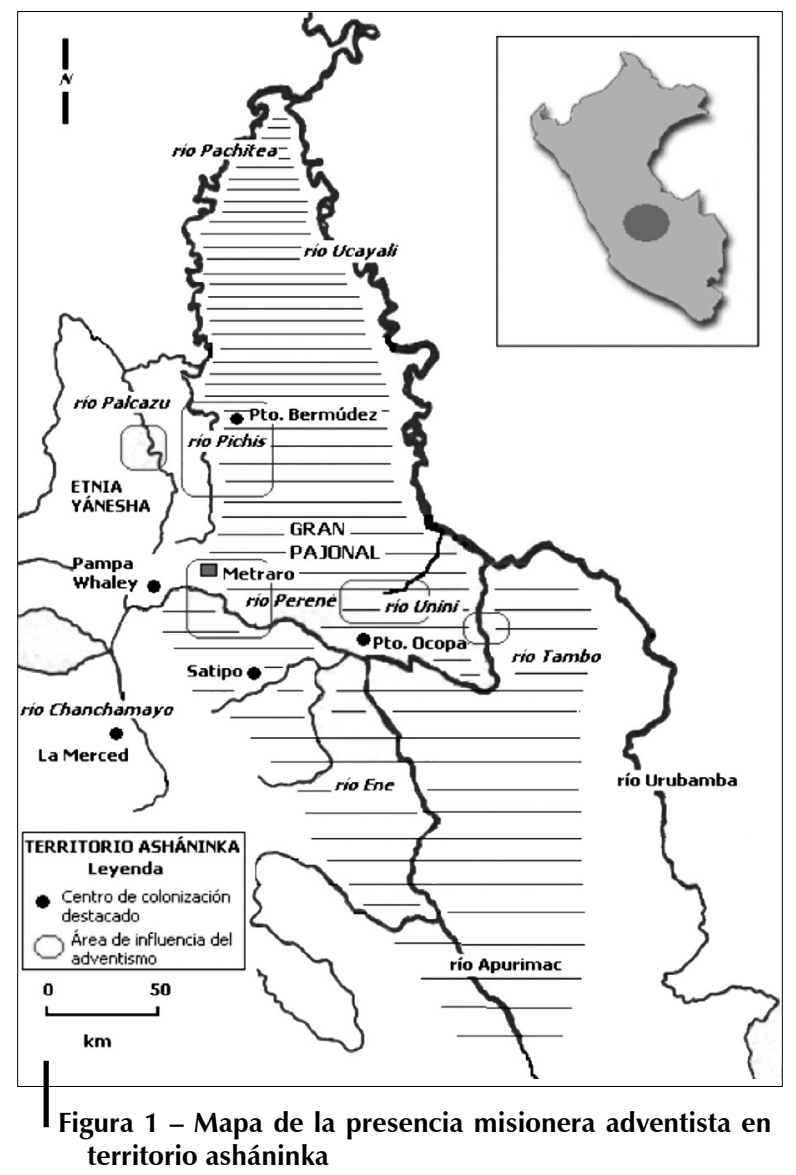

55 «El gran conflicto entre el bien y el mal aumentará en intensidad hasta la consumación de los tiempos. En todas las edades la ira de Satanás se ha manifestado contra la iglesia de Cristo; y Dios ha derramado su gracia y su Espíritu sobre su pueblo para robustecerlo contra el poder del maligno (...) a medida que la iglesia se va acercando a su liberación final, Satanás obrará con mayor poder. Descenderá ‘teniendo grande ira, sabiendo que tiene poco tiempo〉 (Apocalipsis 12: 12). Obrará 〈con grande potencia, y señales, y milagros mentirosos〉 (2 Tesalomicenses 2: 9)» (White, 1975: 12). La doctrina teológica adventista relacionada a la existencia de Satanás y su presencia activa dentro del mundo dentro de la «Gran Confrontación», partió de la interpretación profética de Ellen G. White, reconocida como profetiza y refundadora del movimiento religioso, que desarrolló estos conceptos a partir de visiones (iluminación del Espíritu Santo) que experimentó hacia la década de 1840 y que se mantuvieron, casi en su totalidad, como doctrinas de fe hasta la actualidad. 


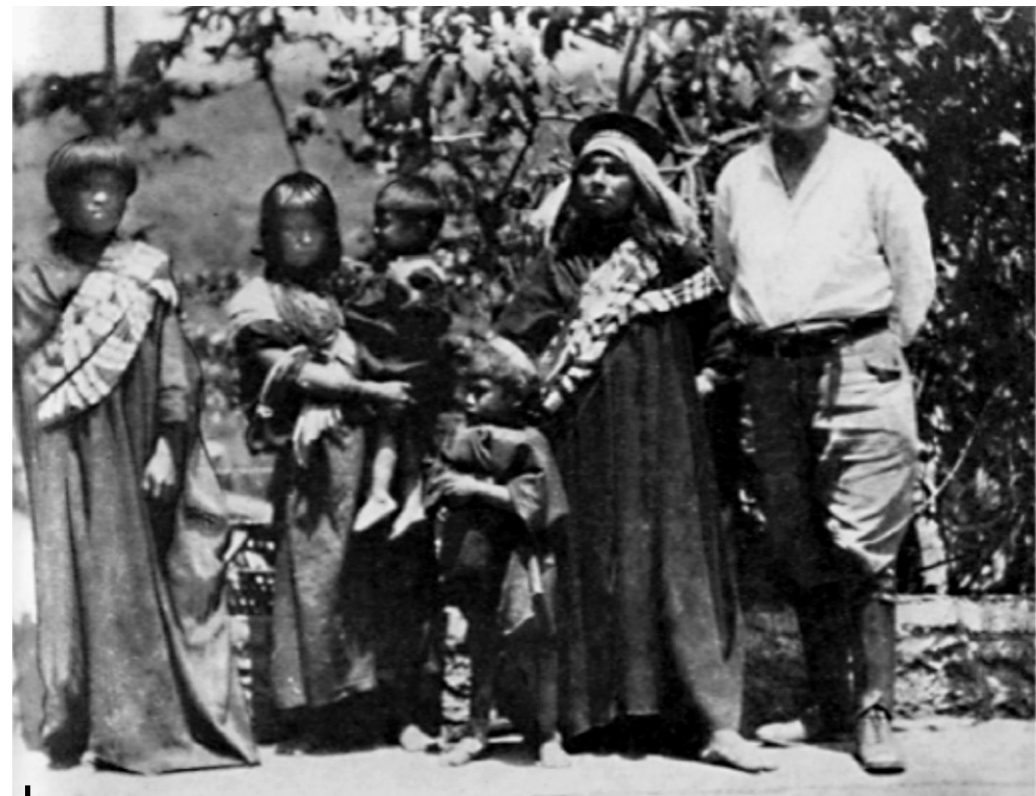

Figura 2 - El capitán Zárate y el misionero Ferdinand Stahl

Probablemente, cerca de la misión de Metraro

Tomada de Stahl (1932: 49)

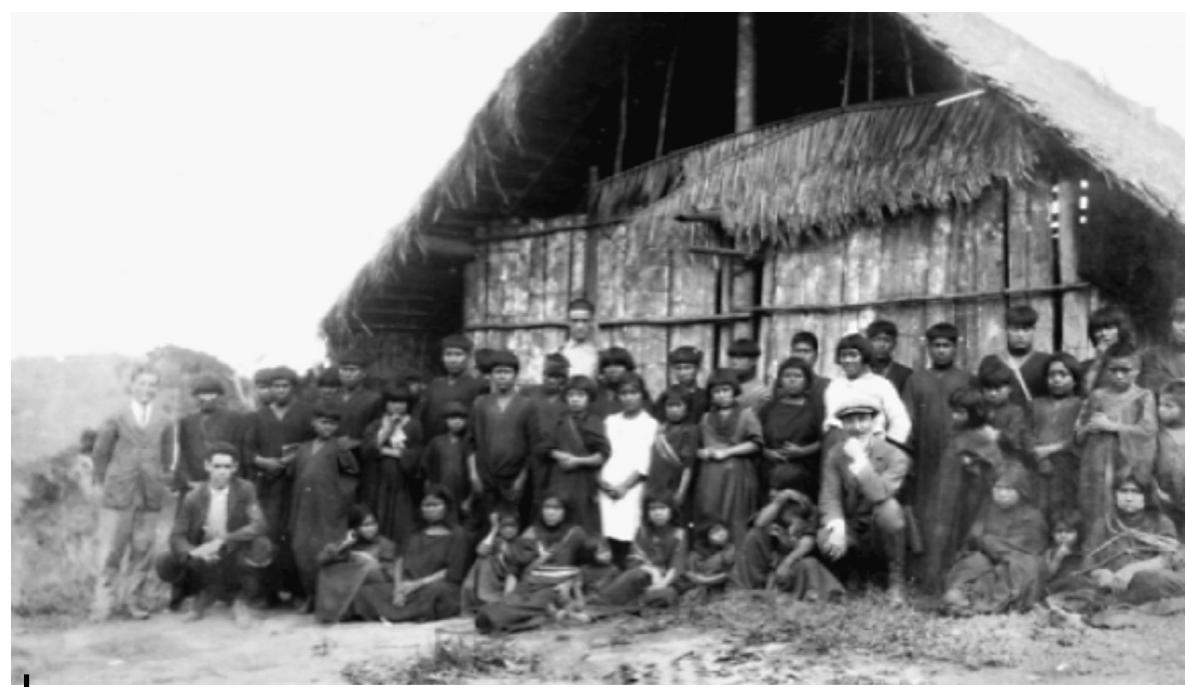

Figura 3 - Miembros de la escuela de la misión de Metraro acompañados por el misionero Juan Ramos, hacia 1926

Tomada de Ramos Gago (2005) 
La enfermedad, hechicería infantil y violencia entre los asháninka desde la perspectiva adventista

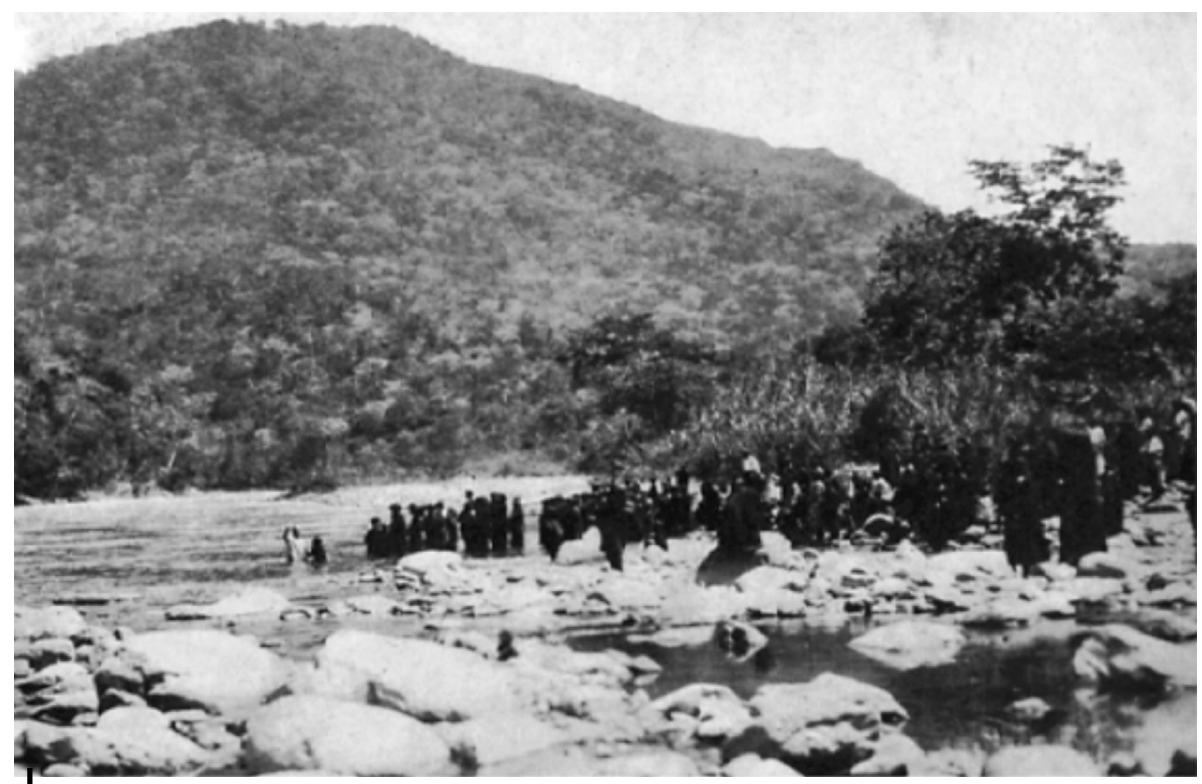

Figura 4 - El «bautismo masivo de Cascadas», celebrado el 24 de agosto de 1928. Fue portada de la Review and Herald el 26 de diciembre de 1929

Tomada de Stahl (1932: 89)

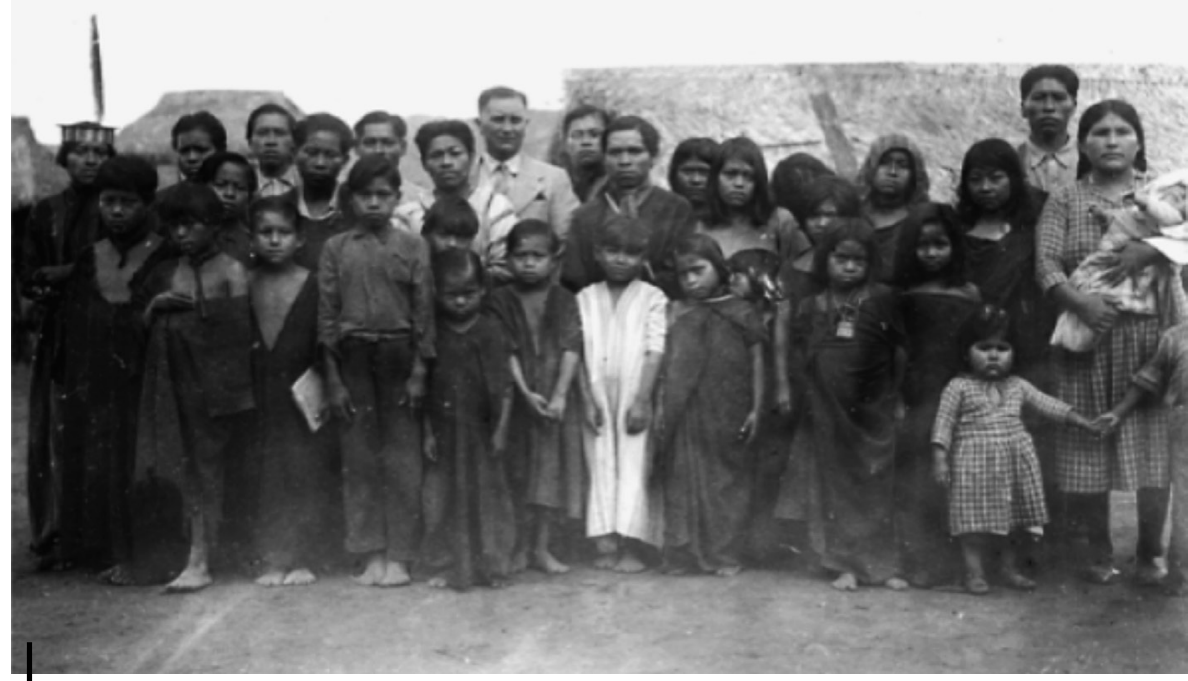

Figura 5 - Feligresía adventista en la estación misionera de Sutziki hacia la década de 1940

Tomada de Ramos Gago (2005) 


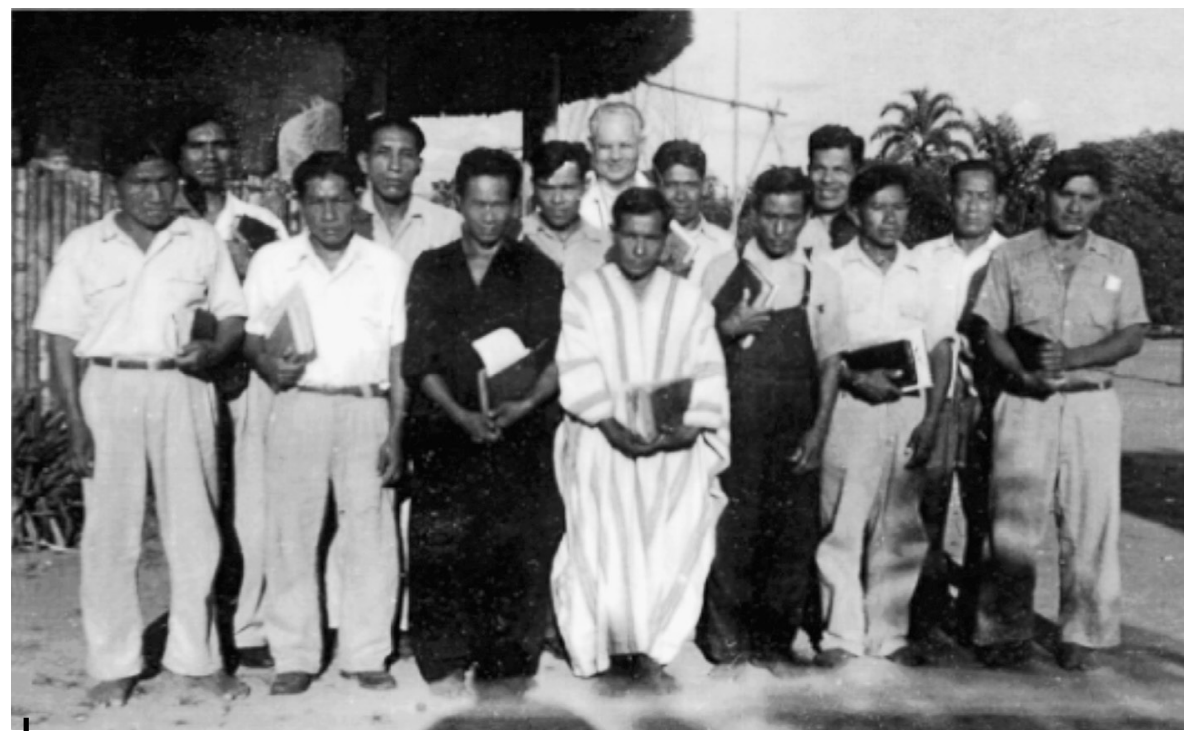

Figura 6 - Grupo de maestros-misioneros asháninkas de Nevati, hacia inicios de la década de 1960

Foto: Merling Alomía

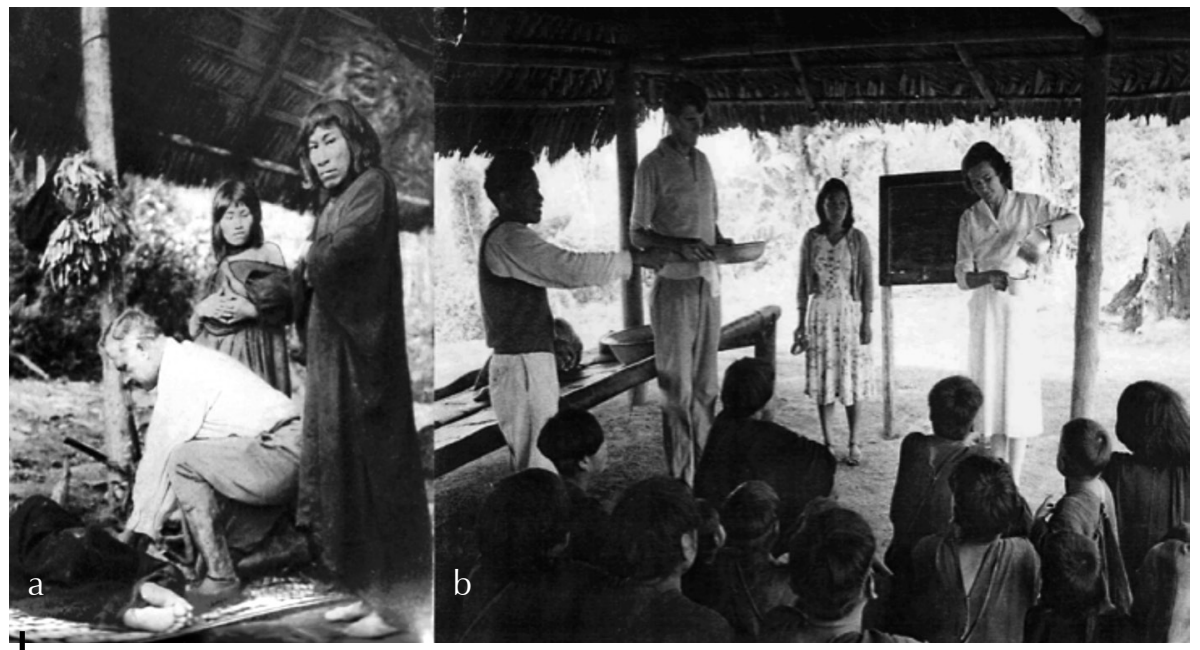

Figura 7 - Misioneros y curación

a: una consulta médica realizada por Stahl a inicios del misionado en Metraro, hacia la década de 1920 (Stahl, 1932: 60); b: los misioneros Neuendorff en el Gran Pajonal, hacia mediados de la década de 1960 (Neuendorff, 2005: 106) 
La enfermedad, hechicería infantil y violencia entre los asháninka desde la perspectiva adventista

\section{Referencias citadas}

ALOMÍA, M., 1996 - ¿Nueva Era o nuevo engaño?, 215 pp.; Lima: Ed. Unión.

ANÓNIMO, 1914 - La vida entre Campas y Amueshas. Hablando con el Sr. Valle Riestra, La Prensa, 18 de julio de 1914.

ANÓNIMO, 1939 - The West Coast Leader, 28 (1431): 10.

ARROYO, F., 1936 - Misión de Sivia. Florecillas de San Antonio, 25 (889): 967.

BARCLAY, F., 1989 - La Colonia del Perené: Capital inglés y economía cafetalera en la configuración de la región de Chanchamayo, 258 pp.; lquitos: CETA.

BODLEY, J., 1970 - Campa Socio-Economic Adaptation; Portland: University of Oregon. Tesis Ph.D.

BODLEY, J., 1881 - Supervivencia tribal en la amazonía: el caso Campa. Amazonía Indígena, 3: 9-13; lquitos.

BOOTON, H., 1958 - El Séptimo Día, 195 pp.; Buenos Aires: Ed. C.E. Sudamericana.

BRESEE, F., 1934 - Advancing in the Peru Mission. South American Bulletin, 10 (9): 6-7.

BROWN, M. \& FERNÁNDEZ, E., 2001 - Guerra de sombras: la lucha por la utopía en la Amazonía peruana, 265 pp.; Lima, Buenos Aires: Centro amazónico de antropología y aplicación práctica, Centro argentino de etnología americana.

BULLÓN PAÚCAR, A., 1999 [1976] - Él nos amaba. La aventura misionera de Stahl entre los Campa, 155 pp.; Lima: Ed. Unión.

BURGAN, W. L., 1923 - Recital of Missionary Adventure, Peril, and Hardship in the Jungle of South America. Review and Herald, 100 (40): 10-12.

CALÍFANO, M. \& GONZALO, J. A., 2004 - La configuración del daño entre los harákmbet. Archivos, 2 (2): 91-116.

CAMINO, A., 1977 - Trueques, correrías e intercambios entre los quechuas andinos y los piros y machiguenga de la Montaña peruana. Amazonía Peruana, 1 (2): 123-140.

CASE, C., 1965 - Fighting a Measles Epidemic in Miritiriani, Peru. Review and Herald, 142 (28): 20-21.

CLEMENT, L. E., 1926 - A Missionary Symposium. Review and Herald, 103 (25): 5-8.

ELICK, J., 1969 - An Ethnography of the Pichis Valley Campa of Eastern Peru; University of California. Tesis Doctoral en Antropología.

FLORES VIDAL, R., 2006 - Fue dicho: «De este fruto no comereis», 248 pp.; Lima:Ed. Unión.

GOW, P., 2007 - La ropa como aculturación en la Amazonía peruana. Amazonía Peruana, 15 (30): 283-304.

GUTHIE, W., 1925 - In the Wilds of Peru. Review and Herald, 102 (10): 9-10.

KUCZYNSKI GODARD, M., 1939 - La Colonia del Perené y sus problemas médico sociales, 50 pp.; Lima: Ediciones de La Reforma Médica. Tercera memoria.

LA SERNA SALCEDO, J. C., 2004 - Misiones adventistas como agentes de modernización y articulación regional en la Selva Central peruana (1920-48). In: Anuario de Ciencias de la Religión 2003. Las religiones en el Perú de hoy: 243-283; Lima: UNMSM, CONCYTEC.

LA SERNA SALCEDO, J. C., 2007 - Misiones, modernidad y civilización de los «salvajes». Reconstrucción histórica del proyecto misionero adventista entre los asháninka de la selva central (1920-1948). Lima: UNMSM. Tesis de Licenciatura en Historia.

LA SERNA SALCEDO, J. C., 2009 - Más allá de la parusía: El enfrentamiento al demonio en el bosque. Religión, política y sociedad asháninka a través de la presencia misionera 
adventista en la selva central peruana (1920-1990); Lima: UNMSM. Tesis de Maestría en Ciencias de la Religión.

LUNDQUIST, H. B., 1938 - Forest Children of Perú. South American Bulletin, 14 (4): 2-3.

MARÍA TERESA (Sor), 1929 - Carta a la Sra. Elvira Rodríguez Lorente (8 de octubre de 1928). Florecillas de San Antonio, 18 (205): 21-23.

MONTGOMERY, O., 1933 - Miracles of God's Grace. Review and Herald, 110 (22): 22-23.

NARBY, J., 1989 - Visions of Land: The ashaninca and resource development in the Pichis Valley in the Peruvian Central Jungle, 363 pp.; University of Stanford. Tesis Doctoral.

NEUENDORFF, S., 2005 - De las orillas del Rin a las riberas del Amazonas: aventuras misioneras en tierras incaicas, 366 pp.; Lima: Universidad Peruana Unión.

OLSON, L. H., 1953 - Visiting our Jungle Mission Stations in Perú. South American Bulletin, 28 (6): 1-2, 5.

ORTíZ, D., 1978 - El Perené: reseña histórica de una importante región de la selva peruana, 465 pp; Lima: San Antonio.

PÉREZ MARCIO, M., 1953 - Los hijos de la selva, 218 pp.; Buenos Aires: Ed. Sudamericana.

PEUGH, V. E., 1929a - Through the Jungles to Iquitos 2. Review and Herald, 106 (1): 16-17.

PEUGH, V. E., 1929b - Through the Jungles to lquitos 3. Review and Herald, 106 (2): 12-13.

RAMOS GAGO, J.P., 2005 - El comienzo de la Obra Misionera Adventista en la Selva Peruana, 117 pp.; Lima: Ed. Unión.

ROJAS ZOLEZZI, E., 1994 - Los asháninka. Un pueblo tras el bosque: contribución a la etnología de los campa de la Selva central peruana, 359 pp.; Lima: Fondo Editorial PUCP.

SANTOS GRANERO, F., 2003 - El enemigo interno: hechicería infantil, insurgencia y los males de la modernidad en la Amazonía peruana. Revista Andina, 36: 161-192; CusCO.

SANTOS GRANERO, F., 2005 - San Cristóbal en la Amazonía: Colonialismo, violencia y hechicería infantil entre los arahuacos de la selva central del Perú. Anthropologica, 23 (23): 43-80; Lima.

SANTOS GRANERO, F., 2009 - Hybrid bodyscapes. A Visual History of Yanesha Patterns of Cultural Change. Current Anthropology, 50 (4): 477-512.

SCHAEFFLER, W., 1931 - Experiences from the Interior of the Perene Region. South American Bulletin, 7 (9): 3-5.

SCHAEFFLER, W., 1934 - Dark Days in the Perene Mission. South American Bulletin, 10 (5): 7.

STAHL, F., 1923a - Among the Chuncho Indians. Review and Herald, 100 (46): 32.

STAHL, F., 1923b - Progress in the Perene. Review and Herald, 100 (51): 22.

STAHL, F., 1924 - Among Indians of the Upper Amazon. Review and Herald, 101 (40): 11.

STAHL, F., 1926 - Among the Heathen Tribes of Upper Amazon». Review and Herald, 103 (27): 13-15.

STAHL, F., 1928 - Zarate is dead. Review and Herald, 105 (44): 20.

STAHL, F., 1929a - God's Guiding Hand. Review and Herald, 106 (34): 18-19.

STAHL, F., 1929b - Amazon Mission, Peru. Review and Herald, 106 (35): 20.

STAHL, F., 1932 - In the Amazon Jungles, 116 pp.; California: Pacific Press Publishing Ass.

STEVENS, H. U., 1925 - The Heroism of Missionary Work. Review and Herald, 102 (3): 9-10, 15. 
La enfermedad, hechicería infantil y violencia entre los asháninka desde la perspectiva adventista

THOMPSON, J. T., 1931 - Work among the Campas. South American Bulletin, 7 (7): 4-5.

WEISS, G., 1975 - Campa cosmology: the world of a forest tribe in South America. Anthropological Papers of the American Museum of Natural History, 52 (5): 219588; New York: American Museum of Natural History.

WHITE, E. G., 1975 - El Gran Conflicto, 784 pp.; Buenos Aires: Ed. Sudamericana. CD. 